\title{
Dynamics and mechanisms of intracellular calcium waves elicited by tandem bubble-induced jetting flow
}

\author{
Fenfang Li ${ }^{a}$, Chen Yang ${ }^{a}$, Fang Yuan ${ }^{b}$, Defei Liao ${ }^{a}$, Thomas Li ${ }^{a}$, Farshid Guilak ${ }^{c, d}$, and Pei Zhong ${ }^{a, 1}$ \\ aDepartment of Mechanical Engineering and Materials Science, Duke University, Durham, NC 27708; ${ }^{b}$ Huacells Corporation, Natick, MA 01760; \\ 'Department of Orthopaedic Surgery, Washington University, St. Louis, MO 63110; and 'Shriners Hospitals for Children, St. Louis, MO 63110
}

Edited by David A. Weitz, Harvard University, Cambridge, MA, and approved December 4, 2017 (received for review August 7, 2017)

\begin{abstract}
One of the earliest events in cellular mechanotransduction is often an increase in intracellular calcium concentration associated with intracellular calcium waves (ICWs) in various physiologic or pathophysiologic processes. Although cavitation-induced calcium responses are believed to be important for modulating downstream bioeffects such as cell injury and mechanotransduction in ultrasound therapy, the fundamental mechanisms of these responses have not been elucidated. In this study, we investigated mechanistically the ICWs elicited in single HeLa cells by the tandem bubble-induced jetting flow in a microfluidic system. We identified two distinct (fast and slow) types of ICWs at varying degrees of flow shear stress-induced membrane deformation, as determined by different bubble standoff distances. We showed that ICWs were initiated by an extracellular calcium influx across the cell membrane nearest to the jetting flow, either primarily through poration sites for fast ICWs or opening of mechanosensitive ion channels for slow ICWs, which then propagated in the cytosol via a reaction-diffusion process from the endoplasmic reticulum. The speed of ICW ( $\left.C_{I C W}\right)$ was found to correlate strongly with the severity of cell injury, with $C_{I C w}$ in the range of $33 \mu \mathrm{m} / \mathrm{s}$ to $93 \mu \mathrm{m} / \mathrm{s}$ for fast ICWs and $1.4 \mu \mathrm{m} / \mathrm{s}$ to $12 \mu \mathrm{m} / \mathrm{s}$ for slow ICWs. Finally, we demonstrated that micrometer-sized beads attached to the cell membrane integrin could trigger ICWs under mild cavitation conditions without collateral injury. The relation between the characteristics of ICW and cell injury, and potential strategies to mitigate cavitation-induced injury while evoking an intracellular calcium response, may be particularly useful for exploiting ultrasoundstimulated mechanotransduction applications in the future.
\end{abstract}

intracellular calcium wave | cavitation bioeffects $\mid$ single-cell analysis cell injury | mechanotransduction

avitation can produce a broad and diverse range of bioeffects during ultrasound therapy, including blood-brain barrier opening (1), tissue ablation and antitumor immune response (2$4)$, targeted drug and gene delivery $(5,6)$, shock wave lithotripsy (SWL) (7), and histotripsy (8). Although cavitation-induced calcium responses have been reported during sonoporation $(5,9-12)$, ultrasonic neuromodulation (13), and with laser-generated cavitation bubbles $(14,15)$, the mechanism whereby the calcium ion $\left(\mathrm{Ca}^{2+}\right)$ transient is initiated, its propagation characteristics, and relationship to downstream bioeffects such as cell injury and mechanotransduction have not been carefully examined (16), especially at the single-cell level. For example, it is unclear how the $\mathrm{Ca}^{2+}$ transients produced during sonoporation, with or without membrane poration, differ from each other quantitatively, and whether different mechanisms are involved $(9,17)$. Particularly, there is growing evidence linking excessive $\mathrm{Ca}^{2+}$ entry and high cytoplasmic $\mathrm{Ca}^{2+}$ concentration with cytotoxicity and associated apoptotic or necrotic cell death during sonication $(12,16,18)$. In addition, mechanotransduction applications such as sonogenetics have gained increasing attention as a noninvasive method for neuromodulation where microbubbles are required to facilitate the cellular response (13). Despite the growing interest and potential, the role of cavitation-induced $\mathrm{Ca}^{2+}$ transients in such mechanotransduction processes is also not well understood. More- over, minimum injury and membrane poration are desirable in sonogenetics and other ultrasonic mechanotransduction applications, e.g., stimulation of stem cell proliferation and differentiation (19, 20). Altogether, a fundamental understanding of the mechanisms underpinning cavitation-induced $\mathrm{Ca}^{2+}$ response and associated bioeffects is critical for exploiting the full potential of ultrasound in targeted molecular delivery, tissue modification, and sonogenetics through mechanosensory responses (13) that can produce the intended therapeutic outcome with minimal adverse effects (16).

In biology, it is well known that a number of extracellular stimuli, such as hormones, neurotransmitters, and physical signals such as mechanical stress, can be transduced via intracellular $\mathrm{Ca}^{2+}$ signaling to regulate a variety of important downstream processes, including exocytosis, contraction, transcription, fertilization, and proliferation $(21,22) . \mathrm{Ca}^{2+}$-mediated signaling can be triggered when extracellular $\mathrm{Ca}^{2+}$ influxes into the cell through plasma membrane, or when $\mathrm{Ca}^{2+}$ is released from intracellular stores, such as the endoplasmic reticulum (ER). This signal transduction is often accompanied by an intracellular $\mathrm{Ca}^{2+}$ wave (ICW), which may further propagate across cell junctions to neighboring cells to trigger intercellular $\mathrm{Ca}^{2+}$ waves for integrative, organ-level response $(23,24)$. Although $\mathrm{Ca}^{2+}$ signaling has been well investigated in biology $(25,26)$ regarding the role of ion channels and intracellular release, limited work has been carried out on the $\mathrm{Ca}^{2+}$ response to membrane poration and cell injury, which occurs frequently in ultrasound therapy with exposure to cavitation. In particular, cavitation can generate impulsive shear flows, and high-strain-rate cell membrane

\section{Significance}

Ultrasound-induced microbubble oscillation can lead to cell injury or mechanotransduction via calcium signaling processes such as intracellular calcium waves (ICWs). However, the mechanisms by which microbubbles stimulate ICWs remain unknown. Using a microfluidic system with highly controlled bubble-cell interaction, we identified two distinct types of ICWs: a fast response correlating with significant membrane poration, and a slow response triggered by calcium influx through stretchactivated ion channels. The fast ICWs, distinguished from those under physiological conditions, are associated with cell injuries. We further elicited ICWs without cell injury by displacing integrinbinding beads on the cell membrane under mild cavitation conditions. This study provides mechanistic insights into ICWs for guiding ultrasound therapy in tissue modification, drug delivery, and cell mechanotransduction.

Author contributions: F. L, F., , F.G., and P.Z designed research: F.L, C., , F., and T.L. performed research; F.L. contributed new reagents/analytic tools; F.L., D.L., T.L., and P.Z. analyzed data; and F.L., F.G., and P.Z. wrote the paper.

The authors declare no conflict of interest.

This article is a PNAS Direct Submission.

Published under the PNAS license.

${ }^{1}$ To whom correspondence should be addressed. Email: pzhong@duke.edu.

This article contains supporting information online at www.pnas.org/lookup/suppl/doi:10. 1073/pnas.1713905115/-/DCSupplemental. 
deformation that may result in transient membrane poration and lethal to sublethal cell injury (27-29). Therefore, from the biological point of view, it would be important to investigate cavitation-induced $\mathrm{Ca}^{2+}$ signaling and other cell response subjected to such high-strain-rate mechanical loading.

However, challenges exist for using current techniques of ultrasound-generated cavitation bubbles to dissect the complex bubble(s)-cell interaction due to the randomness in bubble generation and dynamics. Therefore, the mechanisms responsible for such bioeffects are largely unclear at the fundamental level. Furthermore, bubble-bubble interaction or bubble collapse near a boundary with cells can lead to jet formation $(30,31)$, which is common in therapeutic ultrasound such as SWL and high-intensity focused ultrasound. We have previously developed a microfluidic platform $(28,32)$ with laser-generated tandem bubbles (TBs), and the resultant jetting flow was directed to single patterned cells at different standoff distances $\left(S_{d}\right)$. Such a unique experimental system offers precise control of the dynamic bubble(s)-cell interactions, thus allowing us to dissect various mechanisms responsible for cavitation-induced bioeffects. However, the transient intracellular $\mathrm{Ca}^{2+}$ response, especially in relationship to membrane poration produced by cavitation, has not been investigated.

In this study, we examined the intracellular $\mathrm{Ca}^{2+}$ response in single HeLa cells produced by the directional jetting flow from TB at different $S_{d}$, corresponding to various degrees of membrane deformation. We quantified the propagation speed of ICW $\left(C_{I C W}\right)$, assessed its correlation with cell membrane poration, and further identified two distinct types of intracellular $\mathrm{Ca}^{2+}$ responses. In addition, the mechanisms responsible for each type of $\mathrm{Ca}^{2+}$ response were investigated by selectively modulating extracellular $\mathrm{Ca}^{2+}$ concentration, intracellular $\mathrm{Ca}^{2+}$ release, or $\mathrm{Ca}^{2+}$ influx from stretch-activated ion channels on the cell membrane. More importantly, we have demonstrated that intracellular $\mathrm{Ca}^{2+}$ response can be induced at large $S_{d}$ without injury by attaching micrometersized beads to the cell membrane through the Arg-Gly-Asp (RGD)-integrin link. The observed relation between the characteristics of ICW and cell injury, and potential strategies to mitigate cavitation-induced injury while evoking an intracellular $\mathrm{Ca}^{2+}$ response, may be particularly useful for exploiting sonogenetics and neuromodulation applications in the future.

\section{Results}

Directional Perturbation of Single Cells from TB-Generated Jetting Flow. We utilized a unique microfluidic platform with surface patterning to generate TBs with control of the bubble location, size, orientation, and $S_{d}$ to an individual HeLa cell, captured and grown on an $\mathrm{H}$-shaped island $(32 \times 32 \mu \mathrm{m})$ covered with fibronectin. The cell pattern can minimize the influence of cell size and adhesion characteristics on bubble(s)-cell interaction (Fig. 1 $A$ and $B$ ). TBs (maximum diameter $D_{\max }=50 \pm 2 \mu \mathrm{m}$ ) of antiphase oscillation are produced by two pulsed Neodymium-doped yttrium aluminum garnet (Nd:YAG) laser beams $(\lambda=532 \mathrm{~nm}, 5$ ns pulse duration) with an interpulse delay of about $2.5 \mu$ s. These two laser beams are focused onto a pair of gold dots $(15 \mathrm{~nm}$ thick and $6 \mu \mathrm{m}$ in diameter, with a separation distance of $\left.d_{\mathrm{IB}}=40 \mu \mathrm{m}\right)$ patterned on the glass substrate of a microfluidic channel $(\mathrm{H}=$ $25 \mu \mathrm{m}$, Fig. $1 A$ ). Because the two bubbles are oscillating out of phase, they repel each other by the secondary Bjerknes forces (33), resulting in an outward directional jet formation between $3.0 \mu$ s and $5.0 \mu \mathrm{s}$ (Fig. 1D). This directional jetting flow imposes a highly localized shear stress and stress gradient onto the target cell grown nearby (with a normalized standoff distance $\gamma=$ $S_{d} / R_{\max }=1.2$ to 2.4$)$. By varying $S_{d}$ of the patterned island to the $\mathrm{TB}$, we can modulate the strength of mechanical stimulations imposed on individual cells and examine their intracellular $\mathrm{Ca}^{2+}$ response and other bioeffects under well-controlled experimental conditions. We have previously shown that, when $\gamma<1$ (e.g., $S_{d}=10 \mu \mathrm{m}$ to $\left.20 \mu \mathrm{m}\right)$, a pinpoint membrane poration with sig-
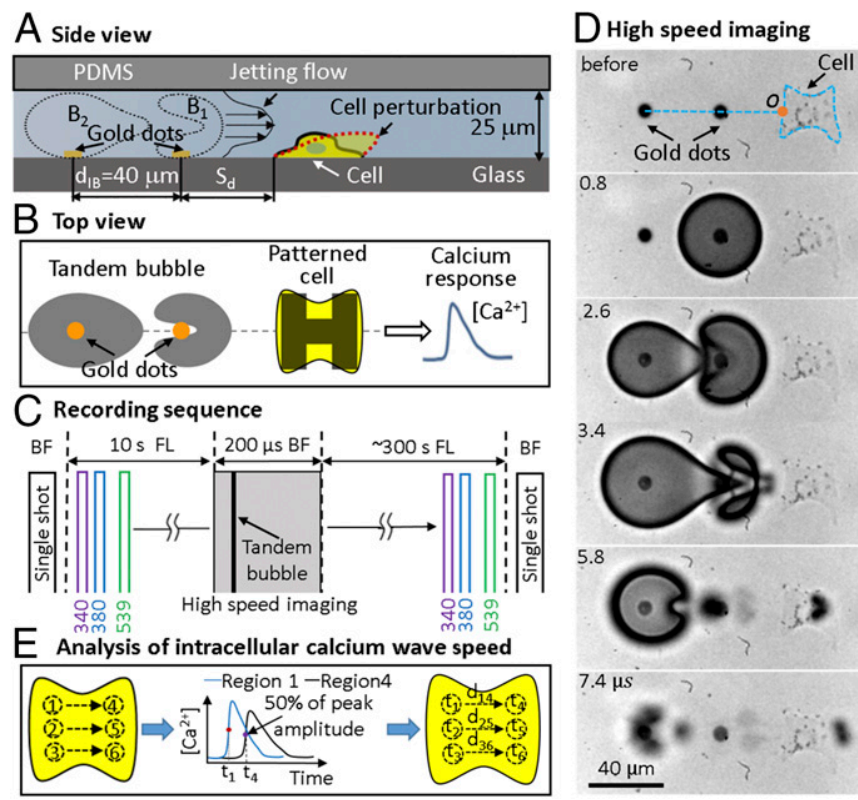

Fig. 1. Schematic diagrams of experimental design and data analysis for spatiotemporal measurements of intracellular $\mathrm{Ca}^{2+}$ transients stimulated by TB interactions. $(A)$ Side view and $(B)$ top view of TB interaction with a single cell grown nearby on an $\mathrm{H}$-shaped pattern in a microfluidic channel. $(C) \mathrm{Re}-$ cording sequences for BF imaging of cell morphology, simultaneous monitoring of intracellular $\mathrm{Ca}^{2+}$ transients (340-, 380-nm excitation) and membrane poration (539-nm excitation) through FL imaging, and high-speed imaging of tandem bubble interaction with jet formation. $(D)$ Example of high-speed image sequence showing the interaction of laser-generated tandem bubble from gold dots with an H-patterned HeLa cell (1- $\mu \mathrm{m}$ RGD-integrin binding beads were attached on cell surface for visualization of membrane deformation). The orange circle (o) represents the intersection of jet axis with cell leading edge (jet impact point), which is used to calculate the original distance of beads to the jet impact point. $(E)$ Protocol used for $C_{I C W}$ analysis.

nificant uptake of membrane impermeant propidium iodide (PI) could be produced, leading to necrosis or apoptosis in majority of the cells treated. In contrast, at $\gamma=1.2$ to 1.6 (e.g., $S_{d}=30 \mu \mathrm{m}$ to $40 \mu \mathrm{m})$, repairable to negligible membrane poration with increased cell survival was observed (28). In this work, we focus on $\mathrm{Ca}^{2+}$ response produced in the sublethal range of $\gamma=1.2$ to 2.4 $\left(S_{d}=30 \mu \mathrm{m}\right.$ to $\left.60 \mu \mathrm{m}\right)$ with repairable or no detectable membrane poration $(28,32)$, which are most relevant to cavitation-mediated macromolecular delivery and sonogenetics applications.

We used sequential fluorescence (FL) imaging to monitor concurrently the intracellular $\mathrm{Ca}^{2+}$ transients (340-, 380-nm excitation of fura-2) and membrane poration (539-nm excitation of PI) produced by TBs. FL imaging was first recorded at baseline level for $10 \mathrm{~s}$ before high-speed imaging of the TB interaction and jet formation, followed by a sequence of $\mathrm{FL}$ imaging of $\mathrm{Ca}^{2+}$ response and PI uptake in the target cell for $300 \mathrm{~s}$ (Fig. 1C). Before and after the TB treatment, changes in cell morphology were also documented by single-shot bright-field (BF) images. Cell injury is assessed by PI uptake and BF cell morphology change. To quantify the propagation of intracellular $\mathrm{Ca}^{2+}$ transient, we have developed a scheme to calculate $C_{I C W}$ based on small-region analysis. The $\mathrm{Ca}^{2+}$ response profiles from the cell leading edge (small regions 1, 2,3 ) to the trailing edge (small regions $4,5,6$ ) are analyzed based on the time of flight in $50 \%$ risetime of individual pairs (Fig. $1 E$; see details in Materials and Methods).

Spatiotemporal Evolution of Intracellular $\mathrm{Ca}^{2+}$ Response and PI Uptake Induced by TB at Various $\boldsymbol{S}_{\boldsymbol{d}}$. Membrane poration has been previously shown to play an important role in the initiation of 
intracellular $\mathrm{Ca}^{2+}$ response produced by cavitation bubbles, yet a detailed understanding of the process is limited $(9,11)$. We therefore first carried out a systematic analysis of the correlation between these two critical events in the biological response of single cells to TBs at different $S_{d}$. Fig. $2 A-E$ shows the image sequences of the typical intracellular $\mathrm{Ca}^{2+}$ response (Top) and PI uptake $($ Bottom $)$ for individual cells treated with TB at $S_{d}=30$ (Fig. 2A), 40 (Fig. $2 B$ and $C$ ), 50 (Fig. $2 D$ ), and 60 (Fig. $2 E$ ) $\mu \mathrm{m}$, respectively. $\mathrm{BF}$ images of the cell morphology before and after the TB treatment are shown in Fig. $2 A-E$, Right. In general, the intensity of the $\mathrm{Ca}^{2+}$ response and PI uptake showed a clear $S_{d}$ dependency, with both signals initiated at the leading edge of the cell facing the jetting flow (indicated by the white arrows) and propagated toward the trailing edge (Fig. $2 A-C$; also see Movie $\mathrm{S} 1$ ). Within the population of individual cells treated by TBs, the probability of an evoked $\mathrm{Ca}^{2+}$ response was found to drop progressively with $S_{d}$ (circles in Fig. $2 F$ ), varying from $100 \%$ at $S_{d}=$ $30 \mu \mathrm{m}$ to no response at $S_{d}=60 \mu \mathrm{m}$. This $S_{d}$ dependency in $\mathrm{Ca}^{2+}$ response is similar to TB-induced membrane poration, and may be associated with the exponentially decaying shear stress experienced by the target cells at increased $S_{d}(28,32)$. The resultant area strain integral (with time) is shown by the diamonds and squares in Fig. $2 F$, representing the upper- and lower-bound values. Using a triad of beads in close proximity, the local area strain of the membrane deformation was calculated based on either the principal strains or trigonometry of the triad, as described previously (28).

Furthermore, the spatiotemporal distributions in the $\mathrm{Ca}^{2+}$ response and PI uptake were found to vary significantly with $S_{d}$. The average $\left[\mathrm{Ca}^{2+}\right]_{\mathrm{i}}$ and PI uptake $(\Delta \mathrm{PI})$ within the individual cells shown in Fig. $2 A-E$ are plotted vs. time in Fig. $2 G$ and $H$, respectively. At $S_{d}=30 \mu \mathrm{m}$ (or $\gamma=1.2$ ), a fast $\mathrm{Ca}^{2+}$ response with short risetime $\left(t_{r}=2.2 \mathrm{~s}\right)$ and large $\left[\mathrm{Ca}^{2+}\right]_{\mathrm{i}}$ change $(523 \mathrm{nM})$ was produced, which was accompanied by a high PI uptake (Fig. $2 A, G$, and $H$ ). In contrast, at $S_{d}=50 \mu \mathrm{m}$ (or $\gamma=2$ ), a slow $\mathrm{Ca}^{2+}$ response with long $t_{r}(99 \mathrm{~s})$ and small $\left[\mathrm{Ca}^{2+}\right]_{\mathrm{i}}$ change $(38 \mathrm{nM})$ was observed, associated with negligible PI uptake; see Fig. $2 D, G$, and $H$. At $S_{d}=40 \mu \mathrm{m}$, a variety of responses ranging from fast to slow $\mathrm{Ca}^{2+}$ transients were obtained, corresponding to high to low PI uptake; see Fig. $2 B, C, G$, and $H$. Finally, at $S_{d}=60 \mu \mathrm{m}$, neither $\mathrm{Ca}^{2+}$ response nor PI uptake was observed (Fig. $2 E-H$ ).

We also noticed substantial variations in the detailed features of the $\mathrm{Ca}^{2+}$ response and PI uptake. At $S_{d}=30 \mu \mathrm{m}$ (Fig. $2 A$ ), a pinpoint rupture with localized and strong PI uptake was often seen at the leading edge of the cell membrane, with PI gradually diffused inside the cytosol, reaching a plateau in about $30 \mathrm{~s}$ (red curve in Fig. $2 \mathrm{H}$, without staining the cell nucleus), indicating repairable membrane poration (28). Importantly, such a localized membrane poration was found to coincide with the initiation of an intracellular $\mathrm{Ca}^{2+}$ response from the same region,
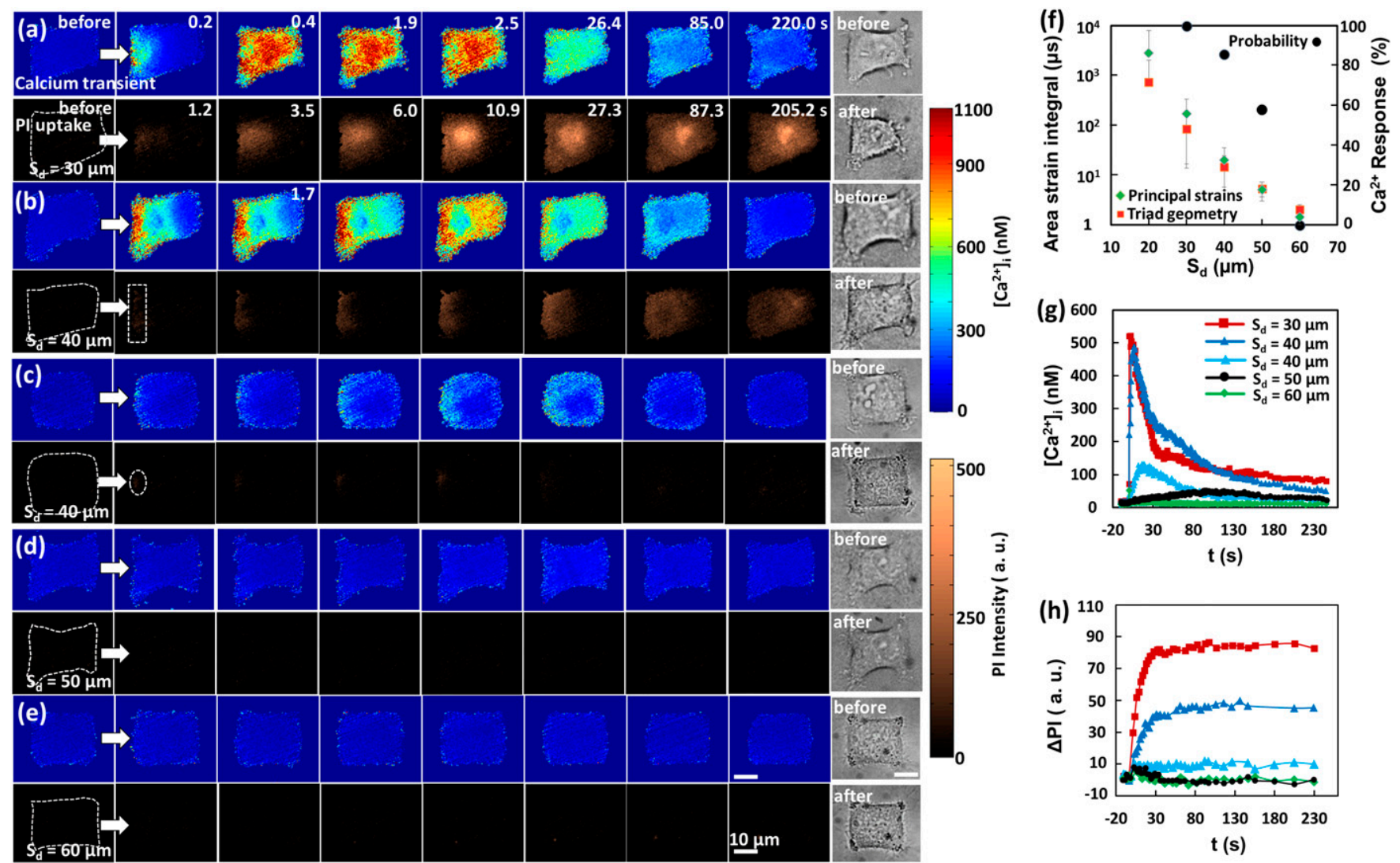

Fig. 2. Typical intracellular $\mathrm{Ca}^{2+}$ response and $\mathrm{PI}$ uptake induced by TB treatment at various $S_{d}$. $(A-E)$ (Left) Image sequences showing (Top) intracellular Ca ${ }^{2+}$ response and (Bottom) PI uptake in five representative individual cells at $S_{d}=30,40$ (two cells), 50, and $60 \mu \mathrm{m}$, respectively. (Right) Single-shot BF images of the cell before and after the treatment. The timing for the image sequences shown in $B-E$ are the same as in $A$ except as otherwise marked on the image. The white arrows indicate the jetting flow direction. The cell contour before treatment is outlined with white dashed lines in the first PI image. Cells were exposed to TBs at $t=0$. Rescaled and more visible $\mathrm{Ca}^{2+}$ and $\mathrm{PI}$ concentration changes in $C$ and $D$ are shown in Fig. S1. (Scale bars, $10 \mu \mathrm{m}$.) $(F)$ Ca ${ }^{2+}$ response probability (black circles) and area strain integral (shown in green diamonds and red squares) at different $S_{d}\left(n=19,21,19\right.$, and 10 for the Ca ${ }^{2+}$ response probability at $S_{d}=30,40,50$, and $60 \mu \mathrm{m}$, respectively). For area strain integral, data at $S_{d}=20,30$, and $40 \mu \mathrm{m}$ were taken from previous study (28), while data for $S_{d}=50$ and $60 \mu \mathrm{m}$ were interpolated. $\mathrm{G}$ and $H$ are the temporal profiles of averaged intracellular $\mathrm{Ca}^{2+}$ concentration and $\mathrm{PI}$ uptake, respectively, inside each individual cell shown in $A-E$. The colors and symbols used for different $S_{d}$ are the same in $G$ and $H$. 
which propagated radially at $t=0.2 \mathrm{~s}$ before spreading out quickly across the cytosol by $t=0.4 \mathrm{~s}$. After initiation, however, the intracellular $\mathrm{Ca}^{2+}$ transient traveled faster than the diffusion of PI in the cytosol. For example, in Fig. $2 A$, the intracellular $\mathrm{Ca}^{2+}$ transient spread from the leading edge to the trailing edge of the cell in less than $0.4 \mathrm{~s}$, compared with about $27.3 \mathrm{~s}$ for PI. This observation suggests that an influx of extracellular $\mathrm{Ca}^{2+}$ at the poration site might trigger the intracellular $\mathrm{Ca}^{2+}$ release from ER based on a reaction-diffusion mechanism known as the "calcium-induced calcium release" (CICR) (34). Such a process can drive the propagation of the $\mathrm{Ca}^{2+}$ transient inside the cell (35), leading to a faster spread of the $\mathrm{Ca}^{2+}$ signal than PI (more details will be provided in Discussion). At $S_{d}=40 \mu \mathrm{m}$, we observed either a relatively homogeneous PI uptake at the cell leading edge with reduced intensity and slow spread (highlighted by the dashed rectangle in Fig. $2 B$ ) or a localized yet weak PI uptake with limited diffusion into the cytosol (highlighted by the dashed circle in Fig. $2 C$ ). The former was accompanied by a more uniform $\mathrm{Ca}^{2+}$ response, propagating as a plane wave across the cytosol, while the latter was accompanied by a less vigorous $\mathrm{Ca}^{2+}$ response (Fig. $2 \mathrm{C}$ and Fig. S1 $A$ ). In comparison, a slow and weak $\mathrm{Ca}^{2+}$ response with negligible PI uptake was generally observed at $S_{d}=50 \mu \mathrm{m}$ (Fig. $2 D$ and Fig. $\mathrm{S} 1 B$ ), which might be triggered by a different mechanism compared with the $\mathrm{Ca}^{2+}$ response in cells with significant membrane poration, such as those treated at $S_{d}=30 \mu \mathrm{m}$.

It is worth noting that, at $S_{d}=30 \mu \mathrm{m}$, the cell deformed and shrank significantly after the TB treatment (see the BF cell image), indicating possible membrane injury and cell detachment from the substrate. In contrast, the cells treated at $S_{d}=40 \mu \mathrm{m}$ to $60 \mu \mathrm{m}$ revealed less to insignificant changes in cell morphology, with better recovery and improved survival rates $(28,32)$. Overall, the reduction in cell spread area after the TB treatment was found to correlate negatively with $S_{d}$ (Fig. S2C), which, together with the loss of F-actin stress fibers, at $S_{d}=30$ and $40 \mu \mathrm{m}$, was confirmed by microscopy (Fig. S2D) (see SI Text for more details). Furthermore, it was found that the reduction in cell spread area generally correlated with the amount of PI uptake (membrane poration) for cells treated at $S_{d}=30,40$, and $50 \mu \mathrm{m}$ (Fig. S3). Altogether, these findings suggest that, although the poration site was resealed quickly after TB treatment, a transient gush of $\mathrm{Ca}^{2+}$ influx, such as induced at $S_{d}=30 \mu \mathrm{m}$, might have already triggered the downstream signal transduction pathways for cytoskeleton rearrangement, and, potentially, cell apoptosis (18).

Quantification of Calcium Response and ICW Propagation. Next, we performed small-region analyses to characterize the spatiotemporal distribution of the evoked intracellular $\mathrm{Ca}^{2+}$ transients, from which $C_{I C W}$ was calculated. Fig. $3 A$ shows two representative examples: cell \#1 (also shown in Fig. $2 A$ ) with a strong $\mathrm{Ca}^{2+}$ response and cell \#2 (also shown in Fig. $2 C$ ) with a mild $\mathrm{Ca}^{2+}$ response. Three pairs of small regions of interest (ROI) along the ICW propagation path were chosen to cover the leading edge (labeled as 1, 2, 3) and trailing edge (labeled as 4, 5,6) of the cell, respectively. Based on the separation distance and the time delay corresponding to $50 \%$ of the maximum intracellular $\mathrm{Ca}^{2+}$ concentration change $\Delta\left[\mathrm{Ca}^{2+}\right]_{\mathrm{i}(\max )}(36), C_{I C W}$ along each individual propagation path (i.e., $1 \rightarrow 4,2 \rightarrow 5,3 \rightarrow 6$ ) was calculated and then averaged to determine the mean of $C_{I C W}$ in each cell (Table S1). Overall, $C_{I C W}$ (mean $\pm \mathrm{SD}$ ) was found to be $57 \pm$ $21 \mu \mathrm{m} / \mathrm{s}$ at $S_{d}=30 \mu \mathrm{m}$, which is significantly higher than the corresponding values of $14 \pm 15 \mu \mathrm{m} / \mathrm{s}$ at $S_{d}=40 \mu \mathrm{m}$ and $4 \pm 3 \mu \mathrm{m} / \mathrm{s}$ at $S_{d}=50 \mu \mathrm{m}$ (Fig. $3 B$ ). The corresponding probability of membrane poration and $\mathrm{Ca}^{2+}$ response at different $S_{d}$ is shown in Fig. $3 C$. At $S_{d}=30 \mu \mathrm{m}$, the probabilities of $\mathrm{Ca}^{2+}$ response and membrane poration are both $100 \%$. In contrast, at $S_{d}=50 \mu \mathrm{m}, 44 \%$ of the cells showed a $\mathrm{Ca}^{2+}$ response with negligible PI uptake.

We also examined the correlations between $\Delta\left[\mathrm{Ca}^{2+}\right]_{\mathrm{i}(\max )}$ (in filled symbols) or $C_{I C W}$ (in open symbols) with PI uptake (Fig.
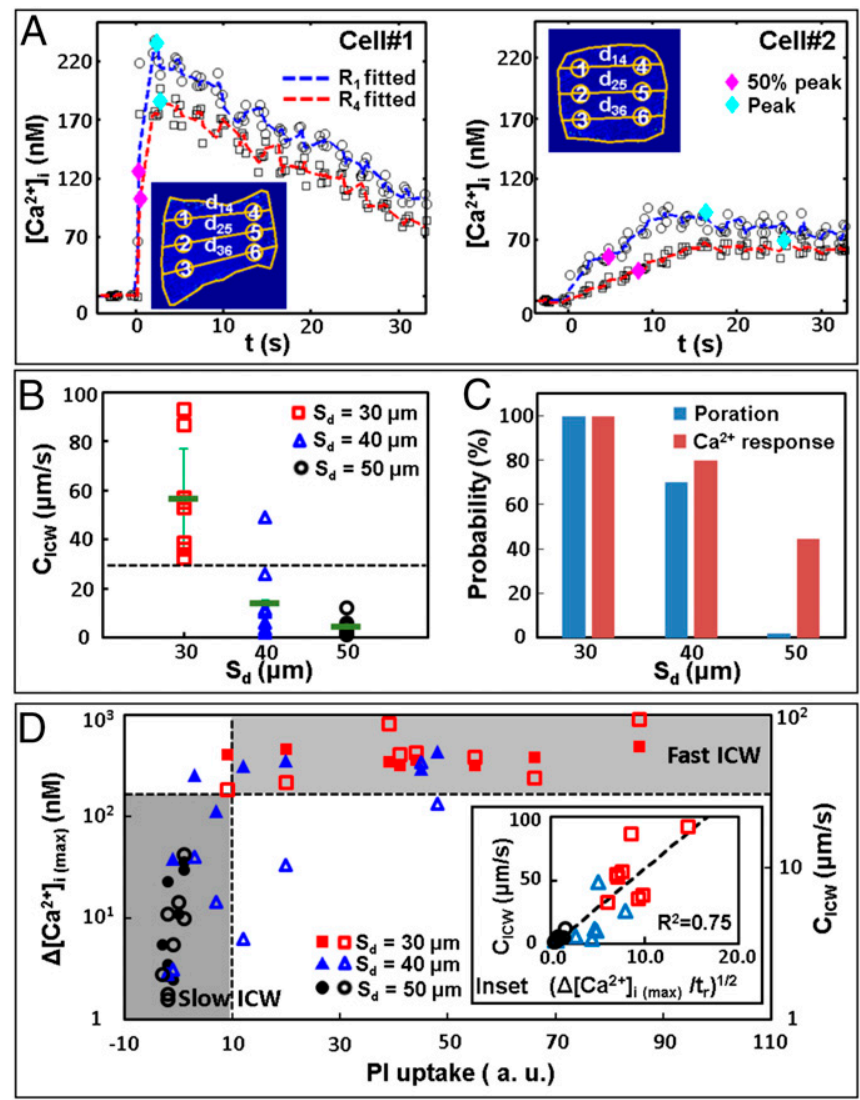

Fig. 3. Quantification of $\mathrm{Ca}^{2+}$ response and ICW propagation. (A) Smallregion analysis for determining $C_{I C W}$. Cells \#1 and \#2 are the cells shown in Fig. $2 A\left(S_{d}=30 \mu \mathrm{m}\right)$ and Fig. $2 C\left(S_{d}=40 \mu \mathrm{m}\right)$, respectively. Insets show the schematics for small-region analysis. $(B) C_{I C W}$ vs. $S_{d}$. The error bars indicate the SD of the calculated averaged uncertainties. (C) Membrane poration and $\mathrm{Ca}^{2+}$ response probability at different $S_{d}$. $(D)$ Correlations of the maximum intracellular $\mathrm{Ca}^{2+}$ concentration change $\Delta\left[\mathrm{Ca}^{2+}\right]_{i(\max )}$ (filled symbols) and $C_{\text {ICW }}$ (open symbols) vs. PI uptake in the cytosol at $S_{d}=30 \mu \mathrm{m}$ to $50 \mu \mathrm{m}$. Results for different $S_{d}$ are labeled with different symbols and colors. The dashed lines indicate separation of data based on the threshold of PI uptake of 10 (a.u.), and $C_{I C W}$ of $30 \mu \mathrm{m} / \mathrm{s}$. (Inset) $C_{I C W}$ vs. the square root of concentration change rate $\left(\Delta\left[\mathrm{Ca}^{2+}\right]_{i(\max )} / t_{r}\right)^{1 / 2}$, where $t_{r}$ is the risetime from baseline to peak concentration. The dashed line represents a linear fitting of the data $\left(R^{2}=0.75\right)$.

$3 D$ ). The results showed two types of $\mathrm{Ca}^{2+}$ responses that may be delineated by thresholds at PI uptake $=10$ (a.u.) and $C_{I C W}=$ $30 \mu \mathrm{m} / \mathrm{s}$, respectively, (see the horizontal dashed lines in Fig. $3 B$ and $D$ ). In particular, the data points in the $S_{d}=50 \mu \mathrm{m}$ group (circles) are below these thresholds (i.e., in the lower left quadrant), characterized by lower values in PI uptake, $C_{I C W}$, and $\Delta\left[\mathrm{Ca}^{2+}\right]_{\mathrm{i}(\max )}$. In comparison, most of the data in the $S_{d}=30 \mu \mathrm{m}$ group (squares) are above these thresholds (i.e., in the upper right quadrant), with higher values in PI uptake and $C_{I C W}$, and with high and yet seemingly saturated $\Delta\left[\mathrm{Ca}^{2+}\right]_{\mathrm{i}(\max )}$. The data in the $S_{d}=40 \mu \mathrm{m}$ group (triangles) fill the transition region between these two extremes. Furthermore, the value of $C_{I C W}$ was found to scale linearly with $\left[\Delta\left[\mathrm{Ca}^{2+}\right]_{\mathrm{i}(\max )} / t_{r}\right]^{1 / 2}$ (Fig. $3 D$, Inset), which is consistent with previous models of ICW propagation $(37,38)$.

Subcellular Features of $\mathrm{Ca}^{2+}$ Signaling Dynamics. Several important features in the initiation and propagation characteristics of ICW further stood out in the time-lapse color-coded 3D images (Fig. $4 A$, and see also Movie S2), with both the height and color representing the $\mathrm{Ca}^{2+}$ concentration inside the cell $\left(\left[\mathrm{Ca}^{2+}\right]_{\mathrm{i}}\right)$. First, $\left[\mathrm{Ca}^{2+}\right]_{\mathrm{i}}$ initially elevated at the leading edge of the cell, 
followed by a rapid spreading of an ICW across the entire cytosol within $2.1 \mathrm{~s}$. During this period, $\left[\mathrm{Ca}^{2+}\right]_{\mathrm{i}}$ at the leading edge was sustained at a high level up to $900 \mathrm{nM}$ while increasing only to $\sim 300 \mathrm{nM}$ at the trailing edge. Thereafter, the overall $\left[\mathrm{Ca}^{2+}\right]_{\mathrm{i}}$ in the cytosol eventually exceeded $500 \mathrm{nM}$ by $6.5 \mathrm{~s}$, except in the cell nucleus region. This global increase of $\left[\mathrm{Ca}^{2+}\right]_{i}$ might be caused by the temporal saturation of $\mathrm{Ca}^{2+}$ buffers by the swiping ICW, which, consequently, enhanced the CICR process (39). These dynamic features can be clearly seen in the temporal line intensity plots along the ICW propagation direction (Fig. 4B) where the $x-t$ plot shows the $\left[\mathrm{Ca}^{2+}\right]_{i}$ profile along the length of line 1 (marked in Fig. 4A) and its variation with time (from bottom to top). An enlarged view of the initial $\left[\mathrm{Ca}^{2+}\right]_{i}$ profiles along line 1 in time sequence (the region inside the dashed box in Fig. $4 B$ ) captures the propagation of the ICW across the cytosol, with the curves showing the temporal evolution of $\left[\mathrm{Ca}^{2+}\right]_{i}$ distribution along the length of line 1 (Fig. 4, Bottom Right). Second, the elicited $\mathrm{Ca}^{2+}$ response was not uniform but rather discrete and accumulative, with $\mathrm{Ca}^{2+}$ puffs and sparks in the appearance of "spikelets" in three dimensions, as shown in Fig. $4 A$ (or "speckles" in two dimensions; see Fig. 2). This observation is consistent with the understanding that there is an extensive and randomly distributed network of ER in the cytosol, which serves as the major intracellular reserve of $\mathrm{Ca}^{2+}(39,40)$. In response to external stimuli, ICWs may be activated on the membrane and propagate inside the cell by the elementary $\mathrm{Ca}^{2+}$ release from ER, which can either operate independently or be coordinated by the local diffusion of $\mathrm{Ca}^{2+}$ or other secondary messenger molecules, such as inositol trisphosphate (InsP3), from one release site to another to form a regenerative ICW through various mechanisms, such as CICR $(22,23)$. More details are given in Discussion.

Third, the elevation of $\left[\mathrm{Ca}^{2+}\right]_{i}$ seemed to propagate faster along the edge than inside the cell, which is evident in the space-time $(y-t)$ plot perpendicular to the ICW propagation direction (i.e., along line 2 , Fig. $4 C$, with the image on the right showing the enlarged view inside the white dashed box during the initiation and early propagation). This feature was also observed in three other cells treated at $S_{d}=30 \mu \mathrm{m}$ or $40 \mu \mathrm{m}$ (Fig. S4).

Mechanistic Study of Intracellular $\mathrm{Ca}^{2+}$ Response Induced by TB Treatment. We observed two different types of $\mathrm{Ca}^{2+}$ responses: a fast ICW for cells treated at $S_{d}=30 \mu \mathrm{m}\left(100 \% \mathrm{Ca}^{2+}\right.$ response with membrane poration) and a slow ICW at $S_{d}=50 \mu \mathrm{m}(44 \%$ $\mathrm{Ca}^{2+}$ response with no membrane poration) (Fig. $3 C$ and $D$ ). Therefore, we conducted a mechanistic investigation to reveal the significance of these two different types of $\mathrm{Ca}^{2+}$ responses. This series of experiments was carried out at $S_{d}=30$ and $50 \mu \mathrm{m}$, with three representative (high, medium, low) $\mathrm{Ca}^{2+}$ response curves shown in each plot of Fig. $5 A-D$. The control experiment with regular medium is shown in Fig. $5 A$. When the culture medium was substituted by $\mathrm{Ca}^{2+}$ free medium (chelated with EGTA), the TB-elicited $\mathrm{Ca}^{2+}$ response could be completely
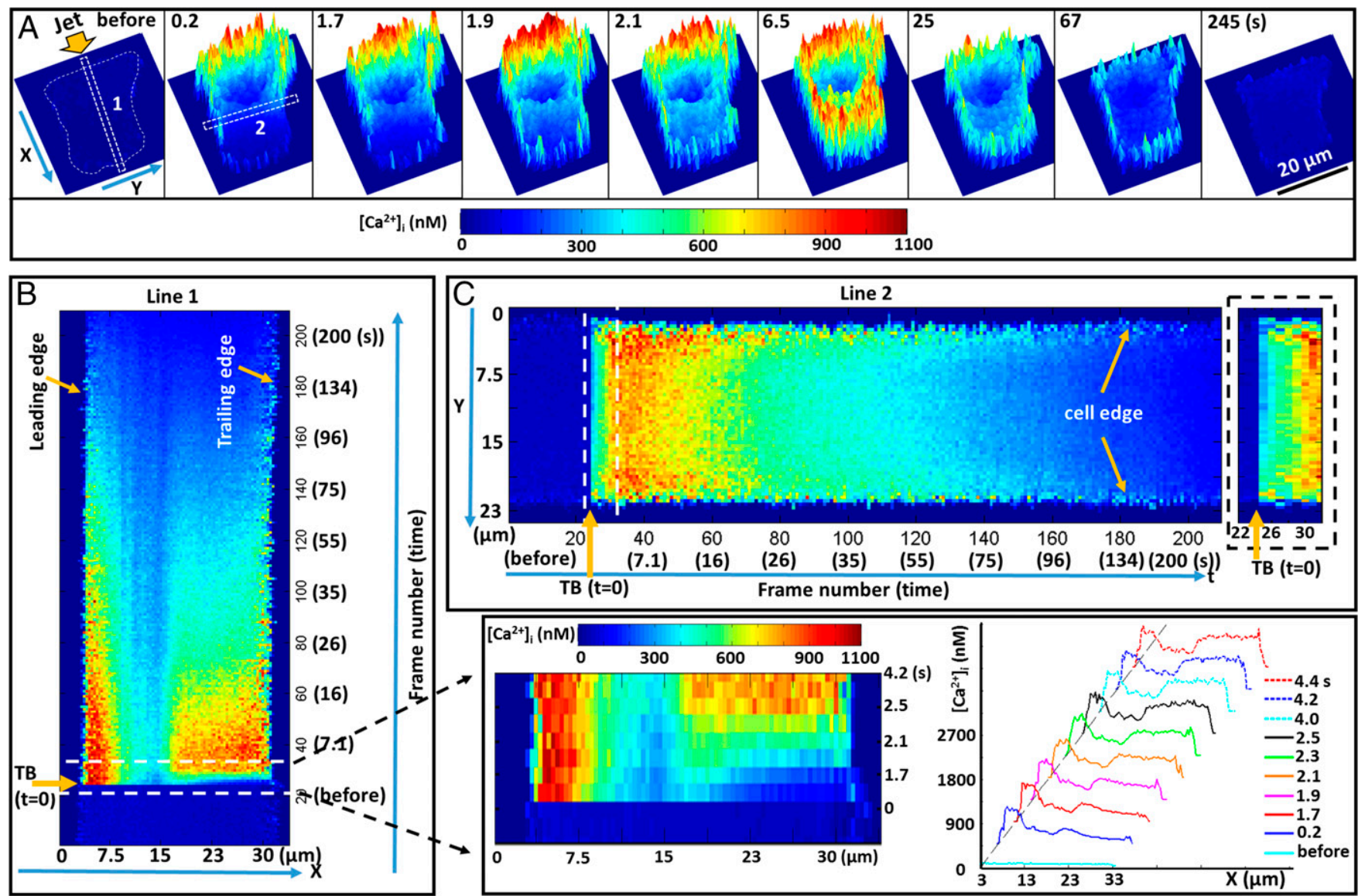

Fig. 4. Dynamic features of ICW initiation and propagation. (A) A representative cell (Fig. 2B) with color-coded 3D images [both the height and color represent the $\mathrm{Ca}^{2+}$ concentration inside the cell $\left.\left(\left[\mathrm{Ca}^{2+}\right]_{i}\right)\right]$; the extracellular background is subtracted by thresholding. $(B)$ The $x-t$ plot of the $\left[\mathrm{Ca}^{2+}\right]_{i}$ profile along the length of rectangle 1 (in the wave propagation direction) marked in A. (Bottom Right) An enlarged view for the region inside the dashed box is shown, with the evolution of $\left[\mathrm{Ca}^{2+}\right]_{i}$ profiles along the length of rectangle 1. (C) The $y$ - $t$ plot of the $\left[\mathrm{Ca}^{2+}\right]_{i}$ profile along the length of rectangle 2 (perpendicular to wave propagation direction) marked in $A$. The $\left[\mathrm{Ca}^{2+}\right]_{i}$ values are averaged across the six-pixel width of rectangles 1 and 2 , respectively. $B$ and $C$ share the same color bar for $\left[\mathrm{Ca}^{2+}\right]_{\mathrm{i}}$. Small-region analysis of wave speed along the edge and inside the cell is summarized in Fig. S4. 
abolished at both $S_{d}$ (Fig. $5 B$ ), indicating that the influx of extracellular $\mathrm{Ca}^{2+}$ is essential for initiating the intracellular $\mathrm{Ca}^{2+}$ response.

The influx of extracellular $\mathrm{Ca}^{2+}$ may take two different pathways: ( $i$ ) through membrane poration sites, as shown in Fig. $2 \mathrm{~A}$ and $B$, and, potentially, (ii) through the opening of stretchsensitive (or mechanosensitive) ion channels $(41,42)$. The molecular expression of mechanosensitive membrane ion channels, such as transient receptor potential melastatin 7 (TRPM7), has been reported in HeLa cells (41) whose function can be blocked by $\mathrm{Gd}^{3+}$. Therefore, we added $100 \mu \mathrm{M} \mathrm{Gd}^{3+}$ to the culture medium to evaluate the effect of mechanosensitive ion channels on TB-elicited $\mathrm{Ca}^{2+}$ response (Fig. $5 C$ ). At $S_{d}=50 \mu \mathrm{m}$, where there
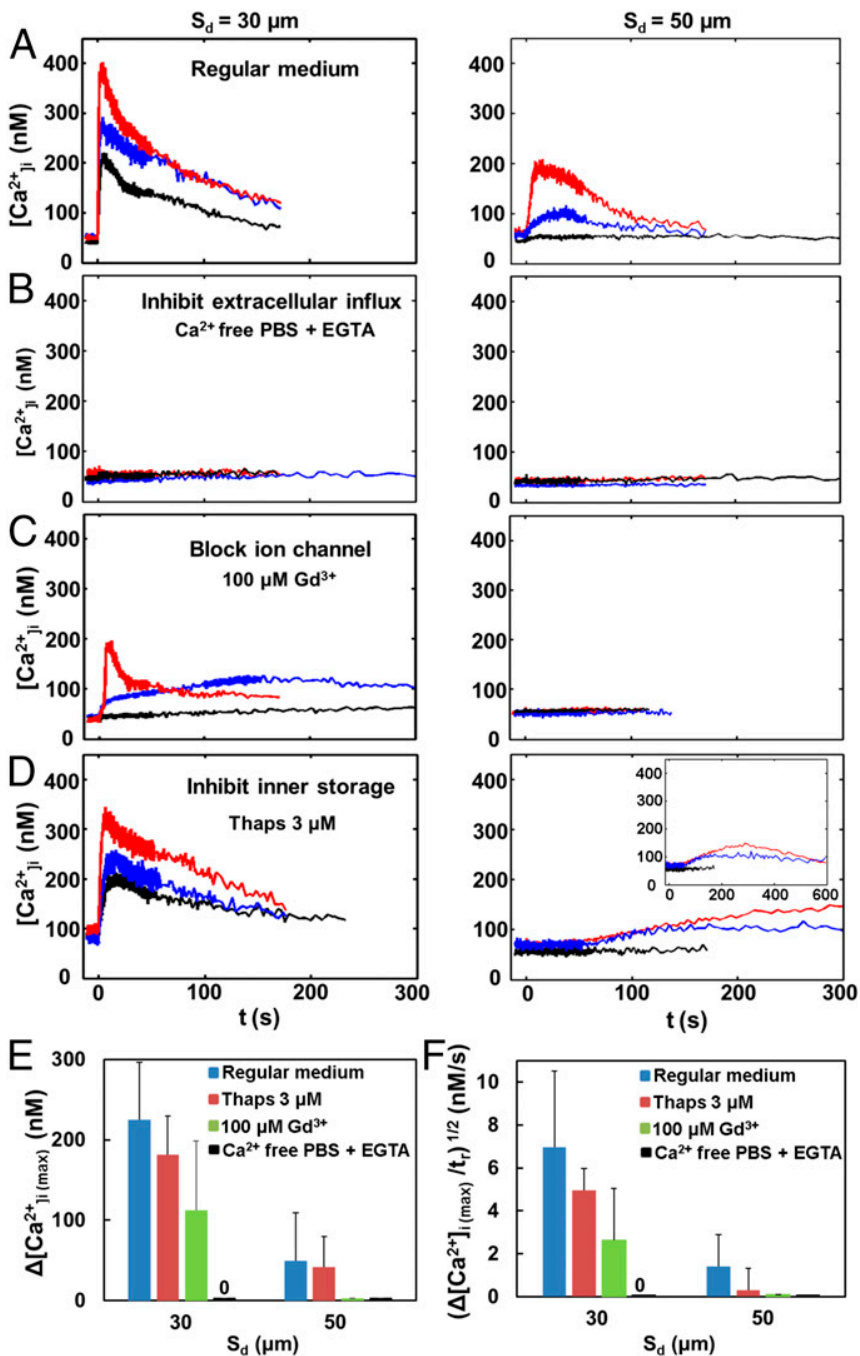

Fig. 5. Mechanistic study of intracellular $\mathrm{Ca}^{2+}$ response induced by $T B$ treatment. $\mathrm{Ca}^{2+}$ response profiles with TB treatment at $S_{d}=30$ and $50 \mu \mathrm{m}(A)$ in regular culture medium, $(B)$ in $\mathrm{Ca}^{2+}$ free culture medium $\left(\mathrm{Ca}^{2+}\right.$ free $1 \times \mathrm{PBS}$ with $0.5 \mathrm{mM}$ EGTA added as $\mathrm{Ca}^{2+}$ chelator), $(C)$ in culture medium with $100 \mu \mathrm{M} \mathrm{Gd}^{3+}$ to block nonspecific mechanosensitive ion channel, and $(D)$ in culture medium with $3 \mu \mathrm{M}$ Thaps to inhibit ER $\mathrm{Ca}^{2+}$-ATPases before TB treatment and thus affecting $\mathrm{Ca}^{2+}$ release. Three representative (high, medium, low) $\mathrm{Ca}^{2+}$ response curves are shown in each plot of $A-D$. ( $E$ and $F$ ) Comparison of $\mathrm{Ca}^{2+}$ responses from groups of individual cells treated by TB in regular culture medium (blue), with $3 \mu \mathrm{M}$ Thaps (red), with $100 \mu \mathrm{M}$ $\mathrm{Gd}^{3+}$ (green), and in $\mathrm{Ca}^{2+}$ free culture medium (black) for $(E) \Delta\left[\mathrm{Ca}^{2+}\right]_{i(\max )}$ and $\left.(F)\left[\Delta\left[\mathrm{Ca}^{2+}\right]_{\mathrm{i}(\max )} / \mathrm{t}_{\mathrm{r}}\right)^{1 / 2}\right]$ vs. $S_{d}=30$ and $50 \mu \mathrm{m}$. Data are shown in mean \pm SD $\left(N=10,3,4\right.$, and 3 at $S_{d}=30 \mu \mathrm{m}$, and $9,3,6$, and 5 at $S_{d}=50 \mu \mathrm{m}$ for regular culture medium, with $3 \mu \mathrm{M}$ Thaps, with $100 \mu \mathrm{M} \mathrm{Gd} d^{3+}$, and in $\mathrm{Ca}^{2+}$ free culture medium, respectively.) was no detectable membrane poration, the $\mathrm{Ca}^{2+}$ response was completely abolished. This result suggests that the slow $\mathrm{Ca}^{2+}$ response elicited under such conditions is mediated by the influx of extracellular $\mathrm{Ca}^{2+}$ through the opening of mechanosensitive ion channels. The $\mathrm{Ca}^{2+}$ response at $S_{d}=30 \mu \mathrm{m}$ was found to be either suppressed with reduced amplitude in $\Delta\left[\mathrm{Ca}^{2+}\right]_{i}$ or, very often, converted from fast to slow $\mathrm{Ca}^{2+}$ responses. Under such conditions, it is likely that the TB-elicited fast $\mathrm{Ca}^{2+}$ response is mediated primarily by membrane poration, while also influenced by mechanosensitive ion channels.

Upon initiation, the transient $\mathrm{Ca}^{2+}$ signal inside the cytosol may spread out via the CICR mechanism through ER that has been well established in the biology literature $(22,23)$. Therefore, we used $3 \mu \mathrm{M}$ thapsigargin (Thaps) to discharge intracellular $\mathrm{Ca}^{2+}$ stores before the TB treatment by inhibiting ER $\mathrm{Ca}^{2+}$-ATPases, which, in turn, will reduce the $\mathrm{Ca}^{2+}$ release from the ER during TB treatment $(43,44)$ (Fig. 5D). At $S_{d}=30 \mu \mathrm{m}$, the $\mathrm{Ca}^{2+}$ response was found to be suppressed in both $\Delta\left[\mathrm{Ca}^{2+}\right]_{\mathrm{i}(\max )}$ and $\left.\left(\Delta\left[\mathrm{Ca}^{2+}\right]_{\mathrm{i}(\max )}\right) / t_{r}\right)^{1 / 2}$ with a reduced $C_{I C W}$ in the range of $4 \mu \mathrm{m} / \mathrm{s}$ to $11 \mu \mathrm{m} / \mathrm{s}$, compared with the regular medium; see Fig. $5 D-F$. At $S_{d}=50 \mu \mathrm{m}$, significantly prolonged $\mathrm{Ca}^{2+}$ responses were observed in cells, indicating that the propagation of the $\mathrm{Ca}^{2+}$ transient in the cytosol was substantially delayed compared with those in the regular medium.

Fig. $5 E$ and $F$ summarizes the variations in $\Delta\left[\mathrm{Ca}^{2+}\right]_{\mathrm{i}(\max )}$ and $\left(\Delta\left[\mathrm{Ca}^{2+}\right]_{\mathrm{i}(\max )} / t_{r}\right)^{\mathbf{1} / 2}$ (proportional to $C_{I C W}$; see Fig. $3 D$, Inset) among the aforementioned culture media. Overall, Thaps, $\mathrm{Gd}^{3+}$, and $\mathrm{Ca}^{2+}$ free media were found to affect the amplitude and propagation speed of the $\mathrm{Ca}^{2+}$ response. The results indicate that extracellular $\mathrm{Ca}^{2+}$ influx is essential for initiating both types of ICWs in the TBtreated HeLa cells: $(i)$ through mechanosensitive ion channels (no injury) in the slow $\mathrm{Ca}^{2+}$ response and (ii) through both membrane poration (with injury) and mechanosensitive ion channels during the fast $\mathrm{Ca}^{2+}$ response. In both cases, the initiated $\mathrm{Ca}^{2+}$ response then propagated through the cytosol via CICR from the ER.

\section{Enhanced Intracellular $\mathrm{Ca}^{2+}$ Response with Integrin-Binding Beads on} the Cell Membrane. In our system of TB-generated jetting flow, both the $\mathrm{Ca}^{2+}$ response and membrane poration show a clear $S_{d}$ dependency that is closely related to the cell membrane deformation (Fig. 2). At large standoff distances, such as $S_{d}=60 \mu \mathrm{m}$, no Ca ${ }^{2+}$ response in a target cell could be induced by the TB, because of the diminished strength of the jetting flow and resultant small cell membrane deformation (28). It was found previously that displacement by TB-induced jetting flow of a $10-\mu \mathrm{m}$ polystyrene bead is larger compared with a small bead of $2 \mu \mathrm{m}$ (45). Furthermore, recent studies have revealed that mechanical force-induced $\mathrm{Ca}^{2+}$ signals at the plasma membrane can be triggered by the displacement of 10- $\mu \mathrm{m}$ fibronectin-coated beads attached to cell surface with laser tweezers (46). Therefore, we hypothesized that shear flow-cell interaction and resultant membrane deformation may be enhanced by attaching micrometer-sized beads on the cell surface, which could amplify the local drag on the cell surface produced by the jetting flow.

Fig. $6 A$ shows an example of TB-cell interaction at $S_{d}=$ $60 \mu \mathrm{m}$, in which $6-\mu \mathrm{m}$ RGD (integrin-binding) beads were attached at the cell's leading edge (such as $b_{1}$ ) and found to be significantly displaced (shown by the dashed yellow line in Fig. $6 \mathrm{~A}, \mathrm{Bottom}$ ) from their original locations (dashed green line for $\mathrm{b}_{1}$ ). Consequently, a mild $\mathrm{Ca}^{2+}$ response was elicited inside the cytosol (see the FL images in Fig. 6B), initiated from local regions with beads at the leading edge nearest to the jetting flow (i.e., $b_{1}$ and $b_{2}$ ), and propagated along the edge and into the cytosol (Fig. $6 B$ and $C$ and Table S2). Moreover, negligible PI uptake was detected (see $\Delta$ PI vs. t profile in Fig. $6 C$ ), indicating no cellular injury. The $C_{I C W}$ from $\mathrm{R}_{1}$ or $\mathrm{R}_{2}$ to $\mathrm{R}_{8}$ was estimated to be $3.71 \mu \mathrm{m} / \mathrm{s}$ or $3.35 \mu \mathrm{m} / \mathrm{s}$, respectively. The low $C_{I C W}$, together with the slow $\mathrm{Ca}^{2+}$ response profile, is similar to the $\mathrm{Ca}^{2+}$ transient initiated by the activation of mechanosensitive ion channels observed in the $S_{d}=50 \mu \mathrm{m}$ group (Fig. $2 D$ ). 


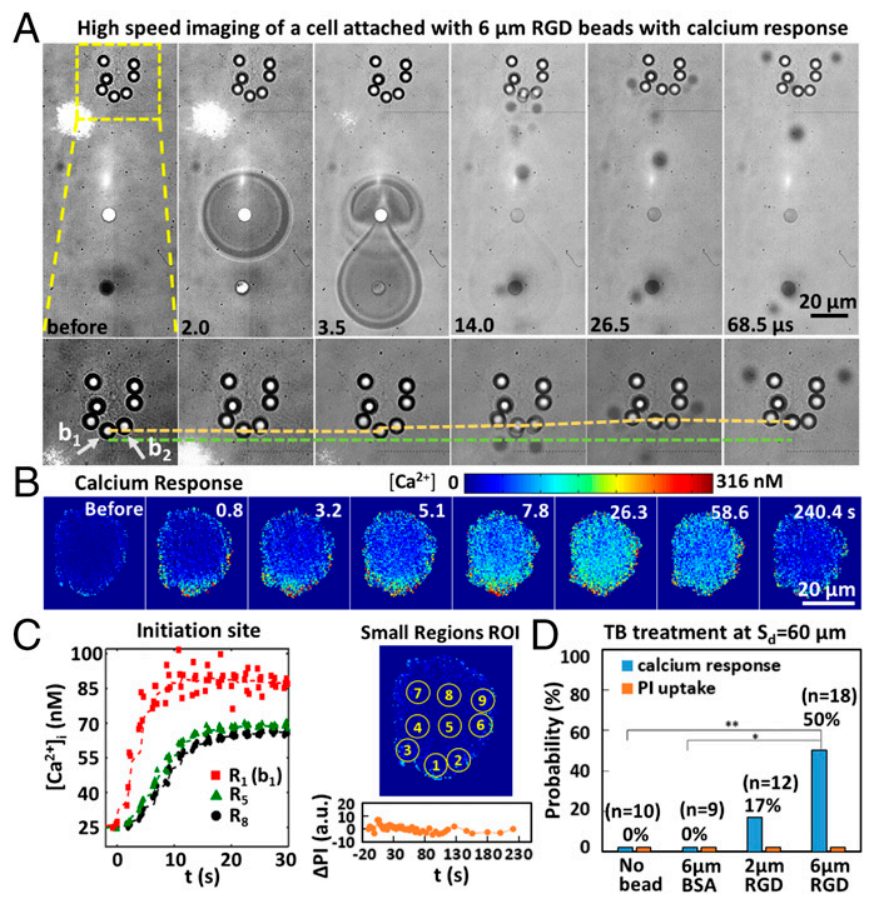

Fig. 6. Beads-enhanced $\mathrm{Ca}^{2+}$ response. (A) (Top) TB interaction with an $\mathrm{H}$-patterned cell with $6-\mu \mathrm{m}$ integrin-binding beads attached on the cell membrane. (Bottom) Enlarged region inside the dashed box in Top; the displacement of an individual bead at the cell leading edge (indicated by the yellow dashed line; the green dashed line serves as a reference). (B) FL image sequence showing $\mathrm{Ca}^{2+}$ response of the cell in $A$. (C) (Left) Time evolution of $\left[\mathrm{Ca}^{2+}\right]_{\mathrm{i}}$ for small ROI on the same cell shown in A. (Right) Locations of the small $\mathrm{ROI}$ on the same cell. PI uptake in the cell is negligible, as shown in Bottom Right ( $\Delta \mathrm{PI}$ vs. $\mathrm{t}) . \Delta \mathrm{PI}$ is in the same scale as shown in Fig. $2 H$. (D) Probability of $\mathrm{Ca}^{2+}$ response and PI uptake in cells with no beads, attached with 2 - and 6- $\mu \mathrm{m}$ RGD-coated integrin-binding beads, or with $6-\mu \mathrm{m}$ BSA-coated nonspecific binding beads treated by TB at $S_{d}=60 \mu \mathrm{m}$. ${ }^{*} P P<0.01$ and $* P<0.05$ from Fisher's exact test; the $P$ value between the $\mathrm{Ca}^{2+}$ response of no beads and $2-\mu \mathrm{m}$ RGD beads is not significant.

We further observed that the enhancement of $\mathrm{Ca}^{2+}$ response at $S_{d}=60 \mu \mathrm{m}$ was bead-size-dependent, increasing from $17 \%$ with $2-\mu \mathrm{m}$ RGD beads to $50 \%$ with $6-\mu \mathrm{m}$ RGD beads (Fig. $6 D$ ). The $\mathrm{Ca}^{2+}$ response probability from $6-\mu \mathrm{m}$ RGD beads is significantly higher compared with that from no beads $(P<0.01)$. In contrast, the results from $2-\mu \mathrm{m}$ RGD beads were not statistically significant compared to that from no beads $(P=0.48)$. No $\mathrm{Ca}^{2+}$ response was observed in the control experiment with $6-\mu \mathrm{m}$ BSA beads that nonspecifically bind to the cell membrane $(P<0.05$ compared with $\mathrm{RGD}$ beads). An enhanced $\mathrm{Ca}^{2+}$ response (66.7\%) without membrane poration was also observed by attaching $6-\mu \mathrm{m}$ RGD beads to the cell membrane with single-bubble $\left(D_{\max }=51 \pm 5 \mu \mathrm{m}\right)$ treatment at $S_{d}=40 \mu \mathrm{m}$, where no $\mathrm{Ca}^{2+}$ response was elicited with no beads or $6-\mu \mathrm{m}$ BSA beads (Fig. S5 $A$ and $B$ ). Furthermore, the enhanced $\mathrm{Ca}^{2+}$ response with RGD beads could be significantly suppressed by inhibiting the mechanosensitive ion channels with $\mathrm{Gd}^{3+}$ or ruthenium red (RR) (Fig. S5C).

Fig. $7 A$ shows an individual cell with beads attached at the leading edge along the jet axis with TB treatment (Fig. $7 A$, Top) that showed no $\mathrm{Ca}^{2+}$ response (FL images in Fig. $7 A$, Bottom). The maximum bead displacement (e.g., $\mathrm{b}_{1}$ in Fig. $7 A$ ) was found to be significantly less than its counterpart in the responsive cell (Fig. 6, and also Fig. 7B, Inset and Movie S3). Moreover, the peak displacements of individual beads on the cell membrane correlated inversely with their original distance to the jet impact point on the cell's leading edge (Fig. $7 C$ ). However, except for $\mathrm{b}_{1}$, the bead's displacement, in general, was not significantly different between the $\mathrm{Ca}^{2+}$ responsive and nonresponsive cells. More importantly, for both 2- and 6- $\mu \mathrm{m}$ beads, the maximum bead displacement (of $b_{1}$ ) was found to be significantly larger in $\mathrm{Ca}^{2+}$ responsive cells than in nonresponsive cells (Fig. 7D). This finding again suggests that large bead displacement or cell membrane stretching is critical for the enhanced $\mathrm{Ca}^{2+}$ response at $S_{d}=60 \mu \mathrm{m}$.

Altogether, we found that the $\mathrm{Ca}^{2+}$ response was enhanced by the amplified membrane stretching from flow-induced displacement of large integrin-binding beads. The force generated needs to be transmitted through integrin and the cytoskeleton (47) to activate mechanosensitive ion channels on the cell membrane (48). The results demonstrate the potential of using integrin-binding beads attached to cell membrane to stimulate mechanotransduction without inflicting cell injury under cavitation-induced shear flows.

\section{Discussion}

We have shown that the controlled directional jetting flow from TB interaction can elicit two distinct types of ICWs with or without membrane poration. The transient $\mathrm{Ca}^{2+}$ response is locally initiated, spreads out directionally, and correlates with the impulsive shear stress-induced cell membrane deformation in an $S_{d}$-dependent manner (Fig. 2). At small $S_{d}(=30 \mu \mathrm{m}, \gamma=1.2)$, a strong $\mathrm{Ca}^{2+}$ response accompanied by significant membrane poration (or injury), highly elevated $\Delta\left[\mathrm{Ca}^{2+}\right]_{\mathrm{i}}(389 \pm 60 \mathrm{nM})$, and fast $C_{I C W}(57 \pm 21 \mu \mathrm{m} / \mathrm{s})$ is produced (Fig. 3). Such a $\mathrm{Ca}^{2+}$ transient is likely to occur during sonoporation $(5,12,49)$, in which a strong and rapid $\mathrm{Ca}^{2+}$ influx at the poration site is primarily responsible for initiating the intracellular $\mathrm{Ca}^{2+}$ response. In our study, chelating extracellular $\mathrm{Ca}^{2+}$ via EGTA abolished the induced response (Fig. 5B, Left), consistent with previous sonoporation studies $(9,12)$. In comparison, at large $S_{d}(=50 \mu \mathrm{m}, \gamma=2)$, a weak and slow $\mathrm{Ca}^{2+}$ response with negligible membrane poration (indicating no injury), mild elevation of $\Delta\left[\mathrm{Ca}^{2+}\right]_{\mathrm{i}}(14 \pm$ $13 \mathrm{nM}$ ), and slow $C_{I C W}(4 \pm 3 \mu \mathrm{m} / \mathrm{s})$ is often induced (Fig. 3).
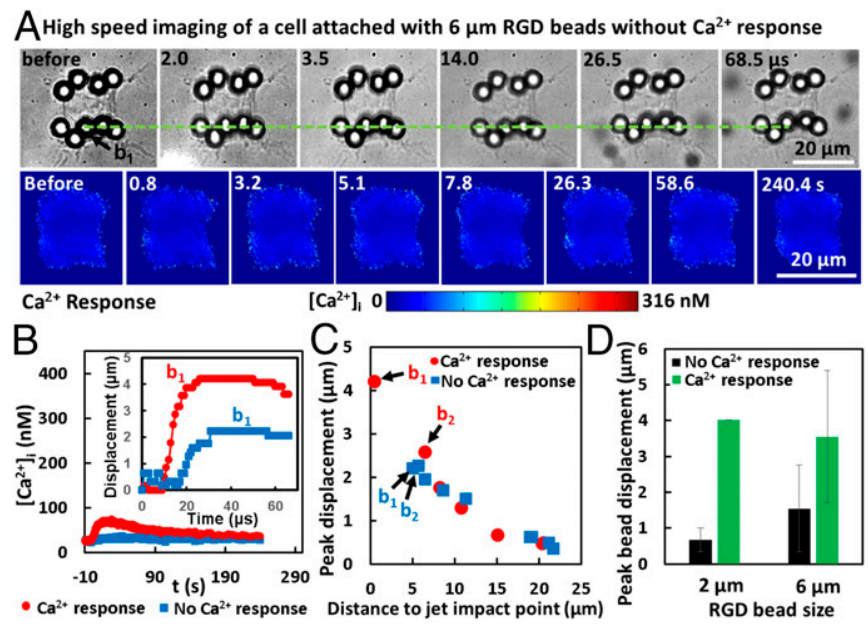

Fig. 7. Mechanisms of beads-enhanced $\mathrm{Ca}^{2+}$ response. (A) An individual cell attached with $6-\mu \mathrm{m}$ RGD-coated integrin-binding beads were treated with TBinduced directional jetting flow at $S_{d}=60 \mu \mathrm{m}$, but with no obvious $\mathrm{Ca}^{2+}$ response. "No $\mathrm{Ca}^{2+}$ response" is defined as when $\Delta\left[\mathrm{Ca}^{2+}\right]_{i(\max )}$ is smaller than $10 \mathrm{nM}$. (Top) The displacement of an individual bead at the cell leading edge (the green dashed line serves as a reference). (Bottom) FL image sequence showing no $\mathrm{Ca}^{2+}$ response of the cell. $(B)$ Time evolution of $\left[\mathrm{Ca}^{2+}\right]_{\mathrm{i}}$ for the two cells shown in Fig. $6 A$ and $A$, respectively. (Inset) The time evolution of the displacement of the beads located in the middle of the cell's leading edge $\left(b_{1}\right)$. (C) Maximum displacement of each bead on cells shown in $B$ as a function of its original distance to the jet impact point (defined by the intersection of jet axis direction with the cell leading edge before TB treatment; see Fig. $1 D$ ). (D) Summary of results showing the peak displacement of the bead with the largest displacement $\left(b_{1}\right)$ on the cells for each group (mean $\pm S D$ ). 
This noninjurious mode of $\mathrm{Ca}^{2+}$ response is triggered by $\mathrm{Ca}^{2+}$ influx through stretch-activated ion channels on the cell membrane, such as TRPM7, which can be blocked by $\mathrm{Gd}^{3+}$ (Fig. 5C, Right). This weak $\mathrm{Ca}^{2+}$ response may be important for ultrasoundstimulated mechanotransduction $(13,16)$. At even greater $S_{d}$ $(\geq 60 \mu \mathrm{m}, \gamma \geq 2.4)$, no appreciable $\mathrm{Ca}^{2+}$ response could be generated, because of the significantly diminished strength of TB-induced jetting flow (28) (Fig. $2 F$ ). These findings provide evidence of discrete mechanisms associated with different magnitudes of mechanical stimulations, resulting in potential pathologic or physiologic $\mathrm{Ca}^{2+}$ signaling.

As shown in Fig. 4, once initiated, the ICW will propagate and spread out in the target cell. Inhibiting $\mathrm{Ca}^{2+}$ release from the ER by Thaps both suppressed the amplitude of $\Delta\left[\mathrm{Ca}^{2+}\right]_{\mathrm{i}}$ and slowed the propagation of ICW (Fig. $5 D-F$ ). $C_{I C W}$ was reduced to the range of $4 \mu \mathrm{m} / \mathrm{s}$ to $11 \mu \mathrm{m} / \mathrm{s}$ for $S_{d}=30 \mu \mathrm{m}$, confirming that TBelicited ICW propagation inside the cytosol was facilitated by the CICR mechanism. It has been shown that the influx of extracellular $\mathrm{Ca}^{2+}(50)$ will activate InsP $_{3}$, which further diffuses inside the cytosol to bind with its receptors (e.g., InsP $\mathrm{P}_{3} \mathrm{Rs}$ ) on the ER to release the stored $\mathrm{Ca}^{2+}$ rapidly ( $\sim 10 \mathrm{~ms}$ to $\left.50 \mathrm{~ms}\right)$. A hierarchical sequence of events will occur, ranging from $\mathrm{Ca}^{2+}$ blips released by individual $\mathrm{InsP}_{3} \mathrm{R}$ channels to $\mathrm{Ca}^{2+}$ puffs formed by the concerted activation of a cluster of $\operatorname{InsP}_{3} \mathrm{Rs}$, to build up an ICW when the local $\left[\mathrm{Ca}^{2+}\right]_{\mathrm{i}}$ reaches a first threshold level of $\sim 0.2 \mu \mathrm{M}$ (40). Our observation of nonuniform $\mathrm{Ca}^{2+}$ response pattern with $\mathrm{Ca}^{2+}$ puffs and sparks in the appearance of spikelets in three dimensions (Fig. $4 A$ ) or speckles in two dimensions (Fig. 2) is in accordance with these previous findings. Thereafter, if the local $\left[\mathrm{Ca}^{2+}\right]_{\mathrm{i}}$ increases further to exceed a second threshold level of $\sim 0.3 \mu \mathrm{M}$ (51), the $\mathrm{Ca}^{2+}$ channels on the ER membrane will begin to shut down slowly $(1 \mathrm{~s}$ to $10 \mathrm{~s})$ to maintain cellular homeostasis $(23,35)$. Ultimately, the excessive $\mathrm{Ca}^{2+}$ in the cytoplasm will be removed through a combined action of buffers, pumps, and exchanges (40). These general features in the dynamics of ICW initiation and propagation are consistent with our experimental observation of TB-induced $\mathrm{Ca}^{2+}$ response profile, which is characterized by an initial short and rapid rise of $\left[\mathrm{Ca}^{2+}\right]_{i}$ to a peak value, followed by a long and gradual decay to the resting level (Figs. $2 G$ and $4 A$ ). The bimodal action of $\mathrm{Ca}^{2+}$ (i.e., a rapid release at low concentration coupled with a gradual shutdown at high concentration) on the InsP $\mathrm{P}_{3} \mathrm{Rs}$ drives successive bursts of regenerative $\mathrm{Ca}^{2+}$ release from the ER to sustain the ICW propagation through the cytosol $(22,23)$.

Besides, it is interesting to note that, in four of the cells treated at $S_{d}=30 \mu \mathrm{m}$ or $40 \mu \mathrm{m}$, we observed that the TB-induced $\mathrm{Ca}^{2+}$ transient propagated faster along the cell boundary (or edge) than inside the cytosol (Figs. $2 B$ and $4 C$ ). The ratio of $C_{I C W}$ at the edge to that at the interior in this subgroup of cells is about 2.4, with $C_{I C W}$ along the cell edge in the range of $\sim 68 \mu \mathrm{m} / \mathrm{s}$ to $108 \mu \mathrm{m} / \mathrm{s}$ (Fig. S4). This observation may be explained by a different mechanism known as calcium-induced calcium influx (CICI) in contrast to CICR. In particular, it has been reported in a few previous studies (52) that unusually rapid $\mathrm{Ca}^{2+}$ transients with $C_{I C W}$ in the range of $\sim 40 \mu \mathrm{m} / \mathrm{s}$ to $1,000 \mu \mathrm{m} / \mathrm{s}$ (at $20^{\circ} \mathrm{C}$ ) may be mediated by CICI, e.g., along flagella or cilia, and even some nonflagellar cells, such as neurons and cancer cells within relatively thin or flat regions (such as in the periphery of HeLa cells). Based on the theory of CICI, it is possible that a focal deformation of the cell membrane may open stretch-activated $\mathrm{Ca}^{2+}$ channels, leading to a local $\mathrm{Ca}^{2+}$ influx that will trigger the sliding of subsurface filaments past each other. Consequently, the nearby membrane will be stretched in sequence to create a traveling motion and, correspondingly, a propagating local $\mathrm{Ca}^{2+}$ influx and thus an ICW along the cell boundary (52).

The physical characteristics of ICW are highly conserved among various species with $C_{I C W}$ typically in the range of $\sim 3 \mu \mathrm{m} / \mathrm{s}$ to $30 \mu \mathrm{m} / \mathrm{s}$ at $20^{\circ} \mathrm{C}(34,35,38)$. Quantitatively, $C_{I C W}$ can be scaled by $\left(J_{\text {eff }} D_{\text {eff }} / C_{0}\right)^{1 / 2}$, where $J_{\text {eff }}$ is the effective Ca ${ }^{2+}$ current density (e.g., $27 \mu \mathrm{M} / \mathrm{s}), D_{\text {eff }}$ is the effective diffusion constant of $\mathrm{Ca}^{2+}$ (e.g.,
$22 \mu \mathrm{m}^{2} / \mathrm{s}$ ), and $C_{0}$ is the $\left[\mathrm{Ca}^{2+}\right]_{\mathrm{i}}$ threshold for $\mathrm{Ca}^{2+}$ channel activation (e.g., $0.5 \mu \mathrm{M})(37)$. Assuming, under physiological conditions, $D_{\text {eff }}$ and $C_{O}$ are constants for each cell type, $C_{I C W}$ is then determined primarily by $\left(J_{e f f}\right)^{1 / 2}$. This feature is consistent with our results in Fig. $3 D$, Inset, especially for the data in the $S_{d}=50 \mu \mathrm{m}$ group and most of the $S_{d}=40 \mu \mathrm{m}$ group with $C_{I C W}$ in the range of $\sim 3 \mu \mathrm{m} / \mathrm{s}$ to $30 \mu \mathrm{m} / \mathrm{s}$ (at $20^{\circ} \mathrm{C}$ ) commonly found among eukaryotic cells $(24,34)$. In contrast, much higher $C_{I C W}(33 \mu \mathrm{m} / \mathrm{s}$ to $93 \mu \mathrm{m} / \mathrm{s})$ was found in the $S_{d}=30 \mu \mathrm{m}$ group, where all cells showed significant membrane poration and cell injury, which may reduce the $\left[\mathrm{Ca}^{2+}\right]_{\mathrm{i}}$ threshold for initiating an $\operatorname{ICW}(53,54)$. Therefore, a high extracellular $\mathrm{Ca}^{2+}$ influx (i.e., greater $J_{e f f}$ ) combined with a low $C_{O}$ may contribute to the significantly elevated $C_{I C W}$ observed in the $S_{d}=30 \mu \mathrm{m}$ group (Fig. $3 B$ ).

Furthermore, it is worth noting that the fast ICW induced at $S_{d}=$ $30 \mu \mathrm{m}$ may reflect the injury response of the target cell, albeit sublethal, to TB-induced repairable membrane poration, which typically resealed in $30 \mathrm{~s}$ (Fig. $2 H$ ). The rapid $\mathrm{Ca}^{2+}$ influx induced under such conditions may accelerate the depolymerization of cytoskeleton filaments to facilitate internal vesicles (lysosomes) to migrate and patch the rupture site through exocytosis $(55,56)$, and, potentially, later on, even the related compensatory response of endocytosis for lesion removal (57). Although the membrane pore is resealed, such a strong $\mathrm{Ca}^{2+}$ response is associated with cytotoxicity, manifested by the loss of F-actin stress fibers, cell shrinkage, and even apoptosis (Fig. S3) observed in this and other studies (58). These collateral injuries, while facilitating the apoptosis of cancer cells in tumor therapy, will limit the range of cavitation-mediated biomedical applications such as gene delivery and neural modulation.

To address this challenge, we have developed a strategy to enhance cavitation-induced $\mathrm{Ca}^{2+}$ response without injury by attaching micrometer-sized beads to the cell membrane through the RGDintegrin link (Fig. 6). With $6-\mu \mathrm{m}$ integrin-binding beads, we found that the $\mathrm{Ca}^{2+}$ response probability was increased to $50 \%$ without membrane poration or injury under cavitation conditions $\left(S_{d}=\right.$ $60 \mu \mathrm{m}, \gamma=2.4)$, which normally do not produce a $\mathrm{Ca}^{2+}$ response without the beads. This enhancement is integrin-binding-specific, since no $\mathrm{Ca}^{2+}$ response was produced with $6-\mu \mathrm{m}$ BSA beads that were nonspecifically attached to cell plasma membrane. The specificity of this response was further confirmed by additional singlebubble-cell interaction experiments (Fig. S5 $A$ and $B$ ), which also demonstrated that the enhanced response was significantly suppressed by $\mathrm{Gd}^{3+}$ or RR (Fig. S5C), two well-known inhibitors of mechanosensitive ion channels. Furthermore, we found that the maximum bead displacement in $\mathrm{Ca}^{2+}$ responsive cells is significantly larger than that in nonresponsive cells attached with $6-\mu \mathrm{m}$ integrinbinding beads (Fig. 7). Altogether, our results suggest that the amplified membrane stretch is transmitted through cell surface integrins (48) to activate mechanosensitive ion channels on the cell membrane, and is critical for the enhanced $\mathrm{Ca}^{2+}$ response at $S_{d}=60 \mu \mathrm{m}$.

In conclusion, we have systematically examined the dynamics and mechanisms of TB-induced ICW at the single-cell level. The knowledge acquired in this work sheds light on how to target different biological effects such as cell injury and apoptosis, drug delivery, and mechanotransduction by tuning the magnitudes of mechanical perturbations through the high-strain-rate shear flows associated with inertial cavitation and dynamic bubblebubble interactions that are prevalent in therapeutic ultrasound applications. Here we used cavitation-induced jetting flow to study the ICW in a highly controlled manner, and the results and insights gained in this work may also apply to single inertial cavitation and other similar mechanical perturbations. Furthermore, the mechanistic insight from this study may offer us opportunities to differentiate the dynamics and mechanisms of pathologic and physiologic $\mathrm{Ca}^{2+}$ responses as a potential diagnostic method to study diseases linked to the dysregulation of $\mathrm{Ca}^{2+}$ signals (such as cardiac disease) and/or monitor treatment at the single-cell level (51). Other future work may focus on utilizing repeated and programmed 
cavitation induced shear flow to stimulate cells for long-term bioeffects such as cell proliferation, differentiation, and gene expression for tissue growth and wound healing.

\section{Materials and Methods}

Fabrication of Microfluidic Chip. The microfluidic chip was made of a polydimethylsiloxane (PDMS, mixing ratio 10:1; Sylgard184; Dow Corning) housing on a patterned glass substrate $(75 \times 38 \times 0.19 \mathrm{~mm})$. A chrome mask was designed with hundreds of repeating units, each of which consists of a pair of gold dots and an $\mathrm{H}$-shaped island. The glass substrate was first patterned with the arrays of gold dots by photolithography, E-beam Evaporation, and meta lift-off. The $\mathrm{H}$-shaped islands were then fabricated at various $S_{d}$ to the gold dots with aligned photolithography. A passivating solution $[0.5 \mathrm{mg} / \mathrm{mL}$ PLL(20) g[3.5]-PEG(2) (SuSOS) in $10 \mathrm{mM}$ Hepes buffer] was coated on the substrate surface to avoid cell adhesion except on the $\mathrm{H}$-shaped regions. After lift-off of the photoresist, the $\mathrm{H}$-shaped islands were covered with fibronectin to contro the cell patterning. The PDMS microchannel with a cross-section of $800 \times 25 \mu \mathrm{m}$ $(\mathrm{W} \times \mathrm{H})$ was produced from a silicon mold using soft lithography. After $\mathrm{O}_{2}$ plasma treatment, the patterned glass substrate and the PDMS microchanne were aligned under a stereomicroscope and bonded together. More detailed fabrication protocol can be found in ref. 32 .

Cell Culture and Handling. HeLa cells (307-CCL-2, p.148; Duke Cell Culture Facility) were routinely maintained in DMEM culture medium (11995-065; ThermoFisher Scientific) supplemented with $10 \%$ FBS in a cell culture in cubator at $37{ }^{\circ} \mathrm{C}$ with $5 \% \mathrm{CO}_{2}$. Cells were trypsinized and resuspended into prewarmed $\left(37 \mathrm{C}^{\circ}\right)$ culture medium to a density of about $5 \times 10^{6}$ cells per milliliter before being injected into the microchannel. The introduced cells were incubated in the microchannel at $37{ }^{\circ} \mathrm{C}$ for $45 \mathrm{~min}$ to allow adhesion onto the fibronectin-coated $\mathrm{H}$-shaped islands. After flushing out nonattached cells, the chip was put back in the incubator for $2 \mathrm{~h}$ with continuous perfusion of culture medium at $0.5 \mu \mathrm{L} / \mathrm{min}$, allowing for the individual cells to fully spread on the fibronectin-coated regions. Thereafter, the culture medium was replaced with fura-2 AM (F1221; ThermoFisher Scientific) working solution [6 $\mu \mathrm{M}$ in Opti-MEM (11058-021; ThermoFisher Scientific)], and the chip was incubated at room temperature in the dark for 40 min with $1 \mu \mathrm{L} / \mathrm{min}$ perfusion rate for loading fura- 2 into the cells. Subsequently, $1 \times$ PBS was used to flush out unloaded fura- 2 AM solution from the microchannel before perfusion of different media under various experimental conditions. For more details, please refer to ref. 32. In mechanistic studies, several different media were used. For example, to remove extracellular $\mathrm{Ca}^{2+}$, the microchannel was filled with $1 \times$ PBS $\left(\mathrm{Ca}^{2+}\right.$ free) with $0.5 \mathrm{mM}$ EGTA to ensure that residual $\mathrm{Ca}^{2+}$ was completely chelated. To monitor concurrent cell membrane poration during $\mathrm{Ca}^{2+}$ response measurement, the microchannel was perfused with $\mathrm{PI}$ solution $(100 \mu \mathrm{g} / \mathrm{mL}$ in Opti-MEM). To block mechanosensitive ion channel, $\mathrm{Gd}^{3+}$ solution [100 $\mu \mathrm{M} \mathrm{GdCl}_{3}$ in $1 \times \mathrm{PBS}$ (with $\mathrm{Ca}^{2+}$ )] was added to the microchannel. To inhibit ER $\mathrm{Ca}^{2+}$ release, cells in the microchannel were incubated with Thaps ( $3 \mu \mathrm{M}$ in Opti-MEM) for 30 min before loading fura-2 (with $3 \mu \mathrm{M}$ Thaps), and subsequently replaced with Opti-MEM ( $3 \mu \mathrm{M}$ Thaps) before experiment. In experiments to facilitate intracellular $\mathrm{Ca}^{2+}$ response at $S_{d}=60 \mu \mathrm{m}$, cells were incubated at $37 \mathrm{C}^{\circ}$ for $30 \mathrm{~min}$ with 2 - or $6-\mu \mathrm{m}$ carboxyl functionalized PS beads (activated with water-soluble carbodiimide), which were pre coated with BSA (2.5\% in PBS) or RGD-containing peptide (Peptite-2000 $100 \mu \mathrm{g} / \mathrm{mL}$ in PBS) for nonspecific binding and integrin-binding to the cell membrane, respectively. The seeding densities of 2 - and $6-\mu \mathrm{m}$ beads were about $1 \times 10^{9}$ and $1 \times 10^{8}$ beads per milliliter, corresponding to about 60 and 6 beads per cell, respectively, on the apical membrane surface. For all measurements, a constant flow rate of $0.5 \mu \mathrm{L} / \mathrm{min}$ was used throughout the experiment.

TB Treatment and Optical Imaging. As shown schematically in Fig. 1, the microfluidic chip with fura-2-loaded cells was fixed on the translation stage of an inverted microscope (Axio Observer Z1; Zeiss). TB was generated next to a target cell by focusing two Q-switched Nd:YAG lasers (New Wave Research) onto a pair of gold dots through a $63 \times$ objective (LD Plan Neofluar; Zeiss). A monochromator (DeltaRAM X; PTI) with shutter was employed to

1. Hynynen K, McDannold N, Sheikov NA, Jolesz FA, Vykhodtseva N (2005) Local and reversible blood-brain barrier disruption by noninvasive focused ultrasound at frequencies suitable for trans-skull sonications. Neuroimage 24:12-20.

2. Hu Z, et al. (2007) Investigation of HIFU-induced anti-tumor immunity in a murine tumor model. J Transl Med 5:34.

3. Kennedy JE (2005) High-intensity focused ultrasound in the treatment of solid tumours. Nat Rev Cancer 5:321-327.

4. Wu F, et al. (2004) Activated anti-tumor immunity in cancer patients after high intensity focused ultrasound ablation. Ultrasound Med Biol 30:1217-1222. create a sequence of light pulses with defined time intervals from a 75-W xenon lamp at excitation wavelengths of 340 and $380 \mathrm{~nm}$ and $539 \mathrm{~nm}$ for fura-2 and PI imaging, respectively. Since PI could also be excited at 340 and $380 \mathrm{~nm}$, a custom-made narrow bandwidth filter $(510 \pm 40 \mathrm{~nm})$ was used for the detection of fura-2 emission at $510 \mathrm{~nm}$ to avoid the overlap with PI emission at $610 \mathrm{~nm}$. A sCMOS (scientific complementary metal-oxide-semiconductor) camera (EDGE 5.5 CL; PCO) was used to record the intracellular fura- 2 and $\mathrm{PI}$ images at 5:1 frame ratio with an exposure time of $50 \mathrm{~ms}$ and an interframe time (IFT) of $0.2 \mathrm{~s}$ for $1 \mathrm{~min}$. Thereafter, fura-2 images were recorded with an IFT at 1, 2, and $5 \mathrm{~s}$ for a duration of 1, 1, and $2 \mathrm{~min}$, respectively, for a total recording time of $300 \mathrm{~s}$, during which one PI image was recorded every five frames of fura- 2 images. After the trigger of the first laser, bubble dynamics alone or together with resultant bead displacement on the cell membrane were captured by a high-speed camera (Imacon 200 or HPV-X, respectively), at 2 million frames per second with 200-ns exposure time. A BF image was taken to register the morphology of the cell immediately before and after the TB treatment; see Fig. 1C. The microscope was programmed to control the illumination shutter, dichroic mirror, and switching between two adjacent alternative positions in the rotating turret of the FL cube for fura-2 and PI imaging. A delay generator (565-8c; Berkeley Nucleonics Corporation) was used to synchronize the two lasers for TB generation and the high-speed cameras for image acquisition. We used $\mu$ Manager software (version1.4; Open Imaging) to communicate and coordinate the operation sequence between the microscope, monochromator, and delay generator. In particular, the FL excitation, filter cube, and recording were automatically switched between fura-2 and PI with a switching interval about $0.7 \mathrm{~s}$.

Measurement of $\left[\mathrm{Ca}^{2+}\right]_{\mathbf{i}}\left[\mathrm{Ca}^{2+}\right]_{i}$ was determined from calibrated ratiometric imaging. The raw FL emission images at $510 \mathrm{~nm}$ from excitation at 340 and $380 \mathrm{~nm}$ were first corrected with background noise subtraction from an area free of cells. The ratiometric value $\left(R=I_{340} / I_{380}\right)$ was then calculated with MATLAB at each pixel, and the averaged ratio within each cell was obtained from a manually segmented region of the cell in the image sequences. The ratio $R$ was related to the $\left[\mathrm{Ca}^{2+}\right]_{\mathrm{i}}$ by

$$
\left[\mathrm{Ca}^{2+}\right]_{\mathrm{i}}=K_{d} \beta\left(R-R_{\min }\right) /\left(R_{\max }-R\right),
$$

where the parameters $R_{\min }=0.157, R_{\max }=4.305, \beta=7.115$, and $K_{d}=113 \mathrm{nM}$ were obtained by using a fura- 2 calibration kit (Invitrogen F6774).

Analysis of $\boldsymbol{C}_{\text {ICw}}$. To quantify the speed of intracellular $\mathrm{Ca}^{2+}$ propagation in HeLa cells after TB and jetting flow treatment, six identical circles, with three near the leading edge and the other three close to the trailing edge of the cell, were drawn manually with the ROI manager in ImageJ. As shown in Fig. $3 A$, the cell leading and trailing edges were nearly perpendicular to the jetting flow direction, and thus they were divided into four equal segments on each side. The centers of the six circles (each with an area of $16.6 \mu \mathrm{m}^{2}$ ) were located at $1 / 4$ length and $3 / 4$ length of the lines linking the points of quadrisection on the two boundaries (Fig. $3 A$ ). The wave propagation distances in three different paths were $d_{14}, d_{25}$, and $d_{36}$. The individually averaged $\left[\mathrm{Ca}^{2+}\right]_{\mathrm{i}}$ over the circles were obtained and curve was fitted using MATLAB, as illustrated in Fig. $3 A$. The risetime at $50 \%$ peak concentration change was determined for the six circles (i.e., $t_{1}, \ldots, t_{6}$; see Fig. $1 E$ ). The $\mathrm{Ca}^{2+}$ wave speeds along the three paths were calculated by $C_{14}=d_{14} /\left(t_{4}-t_{1}\right), C_{25}=d_{25} /\left(t_{5}-t_{2}\right)$, and $C_{36}=d_{36} /\left(t_{6}-t_{3}\right)$. Thereafter, the ICW in the cell was determined by the average of these three speeds: $C_{I C W}=\left(C_{14}+C_{25}+C_{36}\right) / 3$. Table $S 1$ shows a detailed example of calculating $C_{I C W}$ for the two cells presented in Fig. $3 A$.

ACKNOWLEDGMENTS. The authors would like to thank Frank Kosel of Specialised Imaging for providing the Kirana camera with SI-LUX640-400 pulsed laser used in this study. The authors also want to acknowledge the technical support of Ricky Park, Michael Kovach, George Sankin, Holly Leddy, Julia Ross, and Katelyn McCraken, and Edwin Iversen for statistical analysis. This work was supported by National Institutes of Health Grants R03EB017886-01A1, R01-AR48182, and R37-DK052985-20, and by National Science Foundation Grant 1638442.

5. Fan Z, Liu H, Mayer M, Deng CX (2012) Spatiotemporally controlled single cell sonoporation. Proc Natl Acad Sci USA 109:16486-16491.

6. Frenkel $V(2008)$ Ultrasound mediated delivery of drugs and genes to solid tumors. Adv Drug Deliv Rev 60:1193-1208.

7. Zhong P (2013) Shock wave lithotripsy. Bubble Dynamics and Shock Waves, Shock Wave Science and Technology Reference Library, ed Delale CF (Springer, Berlin), Vol 8 , pp 291-338.

8. Roberts WW, et al. (2006) Pulsed cavitational ultrasound: A noninvasive technology for controlled tissue ablation (histotripsy) in the rabbit kidney. J Urol 175:734-738. 
9. Fan Z, Kumon RE, Park J, Deng CX (2010) Intracellular delivery and calcium transients generated in sonoporation facilitated by microbubbles. J Control Release 142:31-39.

10. Meijering BD, et al. (2009) Ultrasound and microbubble-targeted delivery of macromolecules is regulated by induction of endocytosis and pore formation. Circ Res 104: 679-687.

11. Kudo N, Okada K, Yamamoto K (2009) Sonoporation by single-shot pulsed ultrasound with microbubbles adjacent to cells. Biophys J 96:4866-4876.

12. Leow RS, Wan JMF, Yu ACH (2015) Membrane blebbing as a recovery manoeuvre in site-specific sonoporation mediated by targeted microbubbles. $J R$ Soc Interface 12 : 20150029

13. Ibsen S, Tong A, Schutt C, Esener S, Chalasani SH (2015) Sonogenetics is a non-invasive approach to activating neurons in Caenorhabditis elegans. Nat Commun 6:8264.

14. Compton JL, Luo JC, Ma H, Botvinick E, Venugopalan V (2014) High-throughput optical screening of cellular mechanotransduction. Nat Photonics 8:710-715.

15. Gomez-Godinez V, et al. (2015) Laser-induced shockwave paired with FRET: A method to study cell signaling. Microsc Res Tech 78:195-199.

16. Hassan MA, Campbell P, Kondo T (2010) The role of $\mathrm{Ca}^{2+}$ in ultrasound-elicited bioeffects: Progress, perspectives and prospects. Drug Discov Today 15:892-906.

17. Zhou Y, Shi J, Cui J, Deng CX (2008) Effects of extracellular calcium on cell membrane resealing in sonoporation. $J$ Control Release 126:34-43.

18. Orrenius S, Zhivotovsky B, Nicotera P (2003) Regulation of cell death: The calciumapoptosis link. Nat Rev Mol Cell Biol 4:552-565.

19. Fan Z, et al. (2013) Acoustic tweezing cytometry for live-cell subcellular modulation of intracellular cytoskeleton contractility. Sci Rep 3:2176.

20. Schumann D, et al. (2006) Treatment of human mesenchymal stem cells with pulsed low intensity ultrasound enhances the chondrogenic phenotype in vitro. Biorheology 43:431-443.

21. Clapham DE (2007) Calcium signaling. Cell 131:1047-1058

22. Berridge MJ, Lipp P, Bootman MD (2000) The versatility and universality of calcium signalling. Nat Rev Mol Cell Biol 1:11-21.

23. Chun JT, Santella L (2013) Intracellular calcium waves. The Encyclopedia of Biological Chemistry, eds, Lennarz WJ, Lane MD (Academic, Waltham, MA), Vol 2, pp 640-647.

24. Jaffe LF (2010) Fast calcium waves. Cell Calcium 48:102-113.

25. Berridge MJ (2005) Unlocking the secrets of cell signaling. Annu Rev Physio/ 67:1-21.

26. Bootman MD, Berridge MJ (1995) The elemental principles of calcium signaling. Cell 83:675-678.

27. Mohammadzadeh M, Li FF, Ohl CD (2017) Shearing flow from transient bubble oscillations in narrow gaps. Phys Rev Fluids 2:014301.

28. Yuan F, Yang C, Zhong P (2015) Cell membrane deformation and bioeffects produced by tandem bubble-induced jetting flow. Proc Natl Acad Sci USA 112:E7039-E7047.

29. Li F, Chan CU, OhI CD (2013) Yield strength of human erythrocyte membranes to impulsive stretching. Biophys J 105:872-879.

30. Ohl CD, et al. (2006) Sonoporation from jetting cavitation bubbles. Biophys J 91 4285-4295.

31. Sankin GN, Yuan F, Zhong P (2010) Pulsating tandem microbubble for localized and directional single-cell membrane poration. Phys Rev Lett 105:078101.

32. Li F, Yuan F, Sankin G, Yang C, Zhong P (2017) A microfluidic system with surface patterning for investigating cavitation bubble(s)-Cell interaction and the resultant bioeffects at the single-cell level. J Vis Exp 119:e55106.

33. Yuan F, Sankin G, Zhong P (2011) Dynamics of tandem bubble interaction in a microfluidic channel. J Acoust Soc Am 130:3339-3346.

34. Jaffe LF (1993) Classes and mechanisms of calcium waves. Cell Calcium 14:736-745.

35. Dawson SP, Keizer J, Pearson JE (1999) Fire-diffuse-fire model of dynamics of intracellular calcium waves. Proc Natl Acad Sci USA 96:6060-6063.

36. Wang SS, Thompson SH (1995) Local positive feedback by calcium in the propagation of intracellular calcium waves. Biophys J 69:1683-1697.
37. Kupferman R, Mitra PP, Hohenberg PC, Wang SSH (1997) Analytical calculation of intracellular calcium wave characteristics. Biophys J 72:2430-2444.

38. Jaffe LF (1991) The path of calcium in cytosolic calcium oscillations: A unifying hypothesis. Proc Natl Acad Sci USA 88:9883-9887.

39. Bootman MD, Berridge MJ (1996) Subcellular $\mathrm{Ca}^{2+}$ signals underlying waves and graded responses in HeLa cells. Curr Biol 6:855-865.

40. Bootman M, Niggli E, Berridge M, Lipp P (1997) Imaging the hierarchical Ca2+ signalling system in HeLa cells. $J$ Physiol 499:307-314.

41. Numata T, Shimizu T, Okada Y (2007) TRPM7 is a stretch- and swelling-activated cation channel involved in volume regulation in human epithelial cells. $\mathrm{Am}$ Physiol Cell Physiol 292:C460-C467.

42. Yang XC, Sachs F (1989) Block of stretch-activated ion channels in Xenopus oocytes by gadolinium and calcium ions. Science 243:1068-1071.

43. Iwanaga $S$, et al. (2006) Location-dependent photogeneration of calcium waves in HeLa cells. Cell Biochem Biophys 45:167-176.

44. Thastrup O, Cullen PJ, Drøbak BK, Hanley MR, Dawson AP (1990) Thapsigargin, a tumor promoter, discharges intracellular $\mathrm{Ca}^{2+}$ stores by specific inhibition of the endoplasmic reticulum $\mathrm{Ca}^{2+}$-ATPase. Proc Natl Acad Sci USA 87:2466-2470.

45. Lautz J, Sankin G, Yuan F, Zhong P (2010) Displacement of particles in microfluidics by laser-generated tandem bubbles. App/ Phys Lett 97:183701.

46. Kim TJ, et al. (2015) Distinct mechanisms regulating mechanical force-induced $\mathrm{Ca} 2+$ signals at the plasma membrane and the ER in human MSCs. eLife 4:e04876.

47. Schmidt C, Pommerenke H, Dürr F, Nebe B, Rychly J (1998) Mechanical stressing of integrin receptors induces enhanced tyrosine phosphorylation of cytoskeletally an chored proteins. J Biol Chem 273:5081-5085.

48. Matthews BD, Thodeti CK, Ingber DE (2007) Activation of mechanosensitive ion channels by forces transmitted through integrins and the cytoskeleton. Curr Top Membr 58:59-85.

49. Helfield B, Chen X, Watkins SC, Villanueva FS (2016) Biophysical insight into mechanisms of sonoporation. Proc Natl Acad Sci USA 113:9983-9988.

50. Yao Y, Parker I (1994) Ca2+ influx modulation of temporal and spatial patterns of inositol trisphosphate-mediated Ca2+ liberation in Xenopus oocytes. J Physiol 476 $17-28$

51. Berridge MJ (2016) The inositol trisphosphate/calcium signaling pathway in health and disease. Physiol Rev 96:1261-1296.

52. Jaffe LF (2007) Stretch-activated calcium channels relay fast calcium waves propagated by calcium-induced calcium influx. Biol Cell 99:175-184.

53. Carbone E, Marcantoni A, Giancippoli A, Guido D, Carabelli V (2006) T-type channelssecretion coupling: Evidence for a fast low-threshold exocytosis. Pflugers Arch 453 373-383.

54. Weiss $\mathrm{N}$, et al. (2012) A Ca 3 3.2/syntaxin-1A signaling complex controls T-type channel activity and low-threshold exocytosis. J Biol Chem 287:2810-2818.

55. McNeil PL, Steinhardt RA (2003) Plasma membrane disruption: Repair, prevention, adaptation. Annu Rev Cell Dev Biol 19:697-731.

56. Reddy A, Caler E, Andrews NW (2001) Plasma membrane repair is mediated by $\mathrm{Ca}^{2+}$-regulated exocytosis of lysosomes. Mol Biol Cell 12:266a.

57. Idone V, et al. (2008) Repair of injured plasma membrane by rapid Ca2+-dependent endocytosis. J Cell Biol 180:905-914.

58. Heo J, Sachs F, Wang J, Hua SZ (2012) Shear-induced volume decrease in MDCK cells. Cell Physiol Biochem 30:395-406.

59. Chazotte B (2010) Labeling cytoskeletal F-actin with rhodamine phalloidin or fluorescein phalloidin for imaging. Cold Spring Harb Protoc 2010:pdb.prot4947.

60. Elosegui-Artola A, et al. (2014) Image analysis for the quantitative comparison of stress fibers and focal adhesions. PLoS One 9:e107393. 